\title{
GEOTRACES intercalibration of neodymium isotopes and rare earth element concentrations in seawater and suspended particles. Part 2: Systematic tests and baseline profiles
}

\author{
Katharina Pahnke ${ }^{1 *}$, Tina van de Flierdt ${ }^{2}$, Kevin M. Jones ${ }^{3,4}$, Myriam Lambelet $^{2}$, Sidney R. Hemming ${ }^{3}$, \\ and Steven L. Goldstein ${ }^{3}$ \\ ${ }^{1}$ Department of Geology and Geophysics, University of Hawaii, Honolulu, HI 96822, USA \\ ${ }^{2}$ Department of Earth Science and Engineering, Imperial College London, South Kensington Campus, London, SW7 2AZ, UK \\ ${ }^{3}$ Lamont-Doherty Earth Observatory of Columbia University, 61 Route 9W, Palisades, NY 10964, USA \\ ${ }^{4}$ ExxonMobil Production Company, 396 West Greens Road, Houston, TX 77067, USA
}

\begin{abstract}
The large-scale collection of seawater samples and analysis of trace elements and isotopes by the GEOTRACES program call for careful comparison and examination of different methods for sample collection, treatment, and processing. Here we report results for different filter types, sampling bottles, and preconcentration methods for $\mathrm{Nd}$ from seawater. Neodymium isotope ratios and concentrations of unfiltered and filtered seawater using five different filter types agree within 43-56 ppm ( $2 \sigma$ standard deviation, SD) and $10 \%$ (relative $2 \sigma$ standard deviation), respectively. The filter choice therefore has no effect on the measured parameters at the studied locations in the western North Atlantic. This could well be different, however, in areas of high particle concentrations. We therefore strongly recommend filtration of seawater for $\mathrm{Nd}$ isotope and rare earth element concentration measurements. Dissolved ${ }^{143} \mathrm{Nd} /{ }^{144} \mathrm{Nd}$ ratios of seawater collected with Niskin bottles with internal nylon-coated stainless steel springs and trace metal-clean GO-FLO bottles were the same within $43 \mathrm{ppm}(2 \sigma \mathrm{SD})$. The Niskin bottles used here are therefore suitable for the collection of seawater samples for the analysis of ${ }^{143} \mathrm{Nd} /{ }^{144} \mathrm{Nd}$ ratios. Iron coprecipitation and complexation with $\mathrm{HDEHP} / \mathrm{H}_{2} \mathrm{MEHP}$ using $\mathrm{C} 18$ cartridges for the preconcentration of $\mathrm{Nd}$ from seawater yielded the same ${ }^{143} \mathrm{Nd} /{ }^{144} \mathrm{Nd}$ ratios within $37 \mathrm{ppm}(2 \sigma \mathrm{SD})$. Both methods are therefore appropriate. Water column profiles of ${ }^{143} \mathrm{Nd} /{ }^{144} \mathrm{Nd}$ ratios and $\mathrm{Nd}$ concentrations are reported for the North Atlantic (BATS) and North Pacific (SAFe), and profiles of all rare earth elements are reported for BATS. These baseline profiles are recommended for continued quality control and intercalibration by future GEOTRACES cruises.
\end{abstract}

*Corresponding author: E-mail: kpahnke@mpi-bremen.de. Current address: Max Planck Research Group for Marine Isotope Geochemistry, University of Oldenburg, Carl-von-Ossietzky-Str. 9-11, 26129 Oldenburg, Germany

\section{Acknowledgments}

We thank Bob Anderson, Marty Fleisher, and Tim Kenna (LDEO) for the excellent team work before, during, and after the cruises. Special thanks to Greg Cutter, Ken Bruland, and Rob Sherrell for leading the intercalibration effort. We thank the science party of both intercalibration cruises and captain and crew of the R/V Knorr. E. Sholkovitz, G. Bayon, associate Editor P. Croot, and one anonymous reviewer are greatly acknowledged for their constructive reviews. The study was funded through NSF grant OCE-07-52402. This paper is part of the Intercalibration in Chemical Oceanography special issue of Limnology and Oceanography: Methods that was supported by funding from the U.S. National Science Foundation, Chemical Oceanography Program.

DOI 10.4319/lom.2012.10.252
The GEOTRACES program is aimed at characterizing the sources, sinks, and internal cycling of trace elements and isotopes in the global ocean to further our understanding of the processes that determine their distributions. This extensive effort requires the participation and collaboration of laboratories worldwide and makes it necessary to ensure that all data collected are precise and internally consistent, and that accuracy is carefully assessed.

The main goals of the international GEOTRACES intercalibration effort were therefore 1) to intercalibrate all participating laboratories using their individual methods for sample processing and analysis, and 2) to establish whether different shipboard sampling and sample processing procedures affect the concentration and isotopic composition of the analyzed parameters. For $\mathrm{Nd}$ isotope ratios $\left({ }^{143} \mathrm{Nd} /{ }^{144} \mathrm{Nd}\right)$ and rare earth element (REE) concentrations, goal 1 is addressed in van de Flierdt et al. (2012). Goal 2 is addressed here, together with the presentation of seawater profiles of $\mathrm{Nd}$ isotope ratios and REE concentrations 
at two baseline stations in the western North Atlantic at BATS (Bermuda Atlantic Time-Series Study station) and the eastern North Pacific at SAFe (Sampling and Analysis of Iron station).

Most previously published seawater Nd isotopic compositions and $\mathrm{Nd}$ concentrations are reported for unfiltered seawater (e.g., Piepgras et al. 1979; Piepgras and Wasserburg 1980, 1987; Jeandel 1993; Jeandel et al. 1998; Amakawa et al. 2004; Lacan and Jeandel 2004a, 2004b, 2005; Rickli et al. 2009). Alibo and Nozaki (1999) observed that concentrations of REE in unfiltered seawater from the western North Pacific only deviate from truly dissolved concentrations (e.g., filtered at $0.04 \mu \mathrm{m})$ by $2 \%$ to $5 \%$ except for Ce (31\%). This implies that the acid-soluble particulate fraction in seawater from the western North Pacific is relatively small, suggesting that filtration is not required for the analysis of REE. However, until now, no systematic tests have been carried out to verify whether unfiltered and filtered samples, in different oceanic settings (e.g., open ocean, continental margin, surface water, deep water) yield the same $\mathrm{Nd}$ isotope composition and concentration. Similarly, it has not been established whether different filter materials and pore sizes, or different sampling bottles (standard Niskin versus trace metal-clean GO-FLO bottles) affect the $\mathrm{Nd}$ isotopic composition and concentration of seawater.

Here, we report results on the $\mathrm{Nd}$ isotopic composition and $\mathrm{Nd}$ concentration of seawater from several sampling, filtration, and preconcentration tests carried out at BATS and a station on the Virginia continental slope (Virginia slope station). Moreover, we present water column profiles of ${ }^{143} \mathrm{Nd} /{ }^{144} \mathrm{Nd}$ ratios and REE concentrations at BATS, and of ${ }^{143} \mathrm{Nd} /{ }^{144} \mathrm{Nd}$ ratios and $\mathrm{Nd}$ concentrations at SAFe. The results obtained on filtered seawater are compared with previously published results, hydrography at the stations, and particle compositions. We recommend the use of these profiles as 'baseline profiles' for reoccupation and continuous intercalibration in the future, in particular of the deeper samples for which a stronger temporal stability can be expected.

\section{Materials and procedures}

\section{Sample locations}

Samples for this study were collected during two GEOTRACES intercalibration cruises on R/V Knorr. During cruise KN193-6 (Bermuda-Norfolk, June-July 2008), we collected seawater samples at the Bermuda Atlantic Time-Series Study station (BATS, $31^{\circ} 40^{\prime} \mathrm{N}, 64^{\circ} 10^{\prime} \mathrm{W}$ ) from $20 \mathrm{~m}$ and $2000 \mathrm{~m}$ water depth and a full water column profile, as well as seawater from a station on the Virginia continental slope (Virginia slope station, $37^{\circ} 2^{\prime} \mathrm{N}, 74^{\circ} 24^{\prime} \mathrm{W}$ ) from $36 \mathrm{~m}$ water depth (Fig. 1a). During cruise KN195-8 (Honolulu-San Diego, May 2009), we collected a seawater profile at the North Pacific Sampling and Analysis of Iron station $\left(\mathrm{SAFe}, 30^{\circ} \mathrm{N}, 140^{\circ} \mathrm{W}\right.$ ) from 20 to $4500 \mathrm{~m}$ water depth (Table 1). The samples from BATS and the Virginia slope station were used to test the effect of (i) different filter types and pore sizes, (ii) different sampling bottles, and (iii) different REE preconcentration methods on the dissolved $\mathrm{Nd}$ isotopic com- position and REE concentration of seawater. The full water column profiles at BATS and SAFe will serve as 'baseline profiles' and provide the basis for continuous intercalibration when reoccupied during GEOTRACES section cruises in the future.

The hydrography at the baseline stations BATS and SAFe is depicted in the potential temperature-salinity diagrams in Fig. 1b. The water masses found at BATS are Subtropical Mode Water (STMW), marked by constant temperature and salinity, and North Atlantic Deep Water (NADW). The salinity minimum of Antarctic Intermediate Water (AAIW) is only weakly developed. At SAFe, North Pacific Intermediate Water (NPIW) is underlain by North Pacific Deep Water (NPDW).

\section{Sample collection and tests}

The CTD rosette of R/V Knorr (WHOI) that was used on both cruises is a standard rosette on a steel hydrowire with 24 $\times 10$ L Niskin bottles. The Niskin bottles from General Oceanics were equipped with internal stainless steel springs with a $0.25 \mathrm{~mm}$ thick nylon coating, Viton O-rings at the end caps and spigots, and mounted on a powder-coated stainless-steel rosette frame. The Seabird sensors had stainless steel and anodized aluminum housings. To facilitate filtration through filter membranes directly from the Niskin bottles in reasonable time, the bottles were pressurized with compressed (8-10 psi) HEPA-filtered air. The air was distributed to the bottles from a compressor using a manifold that was attached to the air vent of each bottle. The endcaps of the bottles were kept closed using large Quick-Grip bar clamps. For AcroPak500 filter cartridges with paired 0.45 and $0.8 \mu \mathrm{m}$ membranes used at SAFe, pressurizing the Niskin bottles was not necessary.

At BATS $2000 \mathrm{~m}$ and $20 \mathrm{~m}, 10 \mathrm{~L}$ seawater each were filtered through the following filters: Nuclepore polycarbonate tracketched $0.4 \mu \mathrm{m}$ membranes, Nuclepore $1 \mu \mathrm{m}$ membranes, QMA quartz fiber filters with $1 \mu \mathrm{m}$ pore size, Supor filters with paired $0.8 \mu \mathrm{m}$ and $0.45 \mu \mathrm{m}$ polyethersulfone membranes (500 $\mathrm{cm}^{2}$ filtration surface area), Osmonics (Memtrex) filter cartridge with a $0.2 \mu \mathrm{m}$ polycarbonate, track-etched (PCTE) filter membrane (1.6 $\mathrm{m}^{2}$ filtration surface area), and Pall AcroPak200 cartridge filters with paired $0.8 \mu \mathrm{m}$ and $0.2 \mu \mathrm{m}$ Supor polyethersulfone membranes $\left(200 \mathrm{~cm}^{2}\right.$ filtration surface area). Before use, the filter membranes (47 $\mathrm{mm}$ and $90 \mathrm{~mm}$ diameter) and cartridges were leached in $\sim 1 \mathrm{~N}$ ultra-clean, double-distilled ( $\mathrm{Nd}<1 \mathrm{ppt}$ ) hydrochloric acid for $2 \mathrm{~d}$ and thoroughly rinsed with ultra-clean water until the $\mathrm{pH}$ of the ultraclean water was reached. For the membranes, this was done by dripping copious amounts of water on a stack of filter membranes placed on a filter holder to wash out the acid.

In preparation for seawater filtration, the filter membranes were placed into single-stage $47 \mathrm{~mm}$ or $90 \mathrm{~mm}$ diameter all PFA filter holders (Savillex Corp.) and attached to the Niskin bottles using acid-cleaned Teflon-lined Tygon tubing. The filter holders were placed directly above the sampling containers $(10 \mathrm{~L}$ cubitainer). Filtration durations varied depending on the filter material, pore size and membrane diameter used and were shortest at all stations for QMA $1 \mu \mathrm{m}$ and Supor $0.8 \mu \mathrm{m}$ (Fig. 2). 
a)

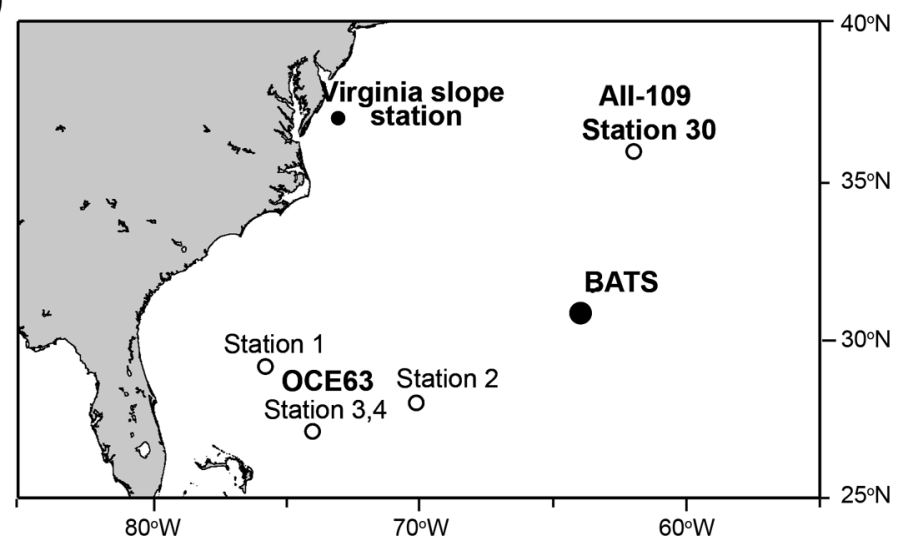

b)

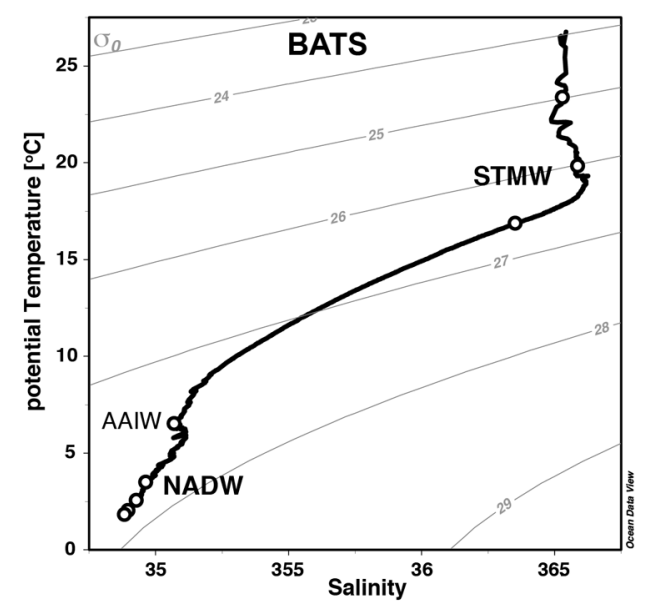

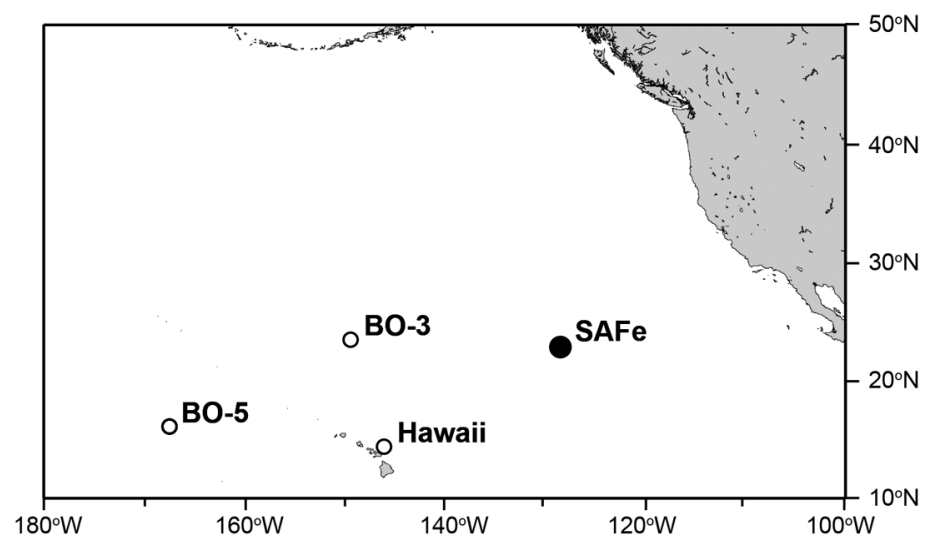

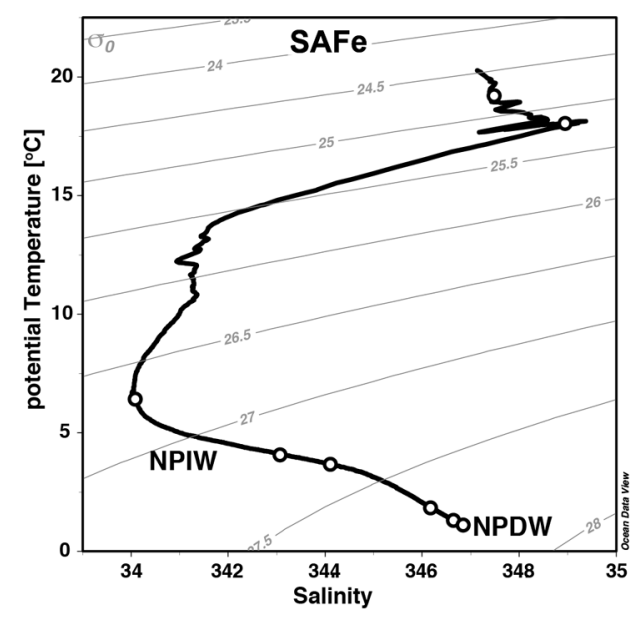

Fig. 1. a) Maps of sampling locations in the North Atlantic: BATS (Bermuda Time Series Station) and Virginia slope station, and in the North Pacific: SAFe (Sampling and Analysis of Iron). Stations of published Nd isotope profiles are also shown (open symbols). In the North Atlantic: All-109-Station 30 (Piepgras and Wasserburg 1987), OCE63-Stations 1-4, combined profile (Piepgras and Wasserburg 1980). In the North Pacific: BO-3 and BO-5 (Amakawa et al. 2009), combined stations around Hawaii (Vance et al. 2004). b) Potential temperature-salinity diagrams for BATS and SAFe. Samples for Nd isotope analyses are indicated by circles. STMW = Subtropical Mode Water, AAIW = Antarctic Intermediate Water, NADW = North Atlantic Deep Water, NPIW $=$ North Pacific Intermediate Water, NPDW = North Pacific Deep Water. Potential density $\left(\sigma_{\theta}\right)$ lines are shown in gray.

Table 1: Station locations, sample depths, and tests carried out

\begin{tabular}{|c|c|c|c|c|c|c|}
\hline Cruise & Station & Latitude & Longitude & $\begin{array}{c}\text { Water depth } \\
{[\mathrm{m}]}\end{array}$ & $\begin{array}{c}\text { Sampling } \\
\text { device }\end{array}$ & Tests \\
\hline KN193-6 & BATS & $31^{\circ} 45^{\prime} \mathrm{N}$ & $64^{\circ} 06^{\prime} \mathrm{W}$ & $\begin{array}{c}15 \\
20 \\
2000 \\
2000 \\
20-4500\end{array}$ & $\begin{array}{l}\text { tow-fish } \\
\text { Niskin } \\
\text { GO-FLO } \\
\text { Niskin }\end{array}$ & $\begin{array}{c}\text { pre-concentration } \\
\text { filter, sampling bottles } \\
\text { pre-concentration, sampling bottles } \\
\text { filter, sampling bottles } \\
\text { baseline profile (Supor } 0.45 \mathrm{~mm} \text { ) }\end{array}$ \\
\hline KN193-6 & Slope & $37^{\circ} 02^{\prime} \mathrm{N}$ & $74^{\circ} 24^{\prime} \mathrm{W}$ & 36 & Niskin & filter \\
\hline KN195-8 & $\mathrm{SAFe}$ & $30^{\circ} 00^{\prime} \mathrm{N}$ & $140^{\circ} 00^{\prime} \mathrm{W}$ & $20-4500$ & Niskin & baseline profile (AcroPak $0.8 / 0.45 \mathrm{~mm}$ ) \\
\hline
\end{tabular}

The filtered samples were collected directly into precleaned low-density polyethylene collapsible containers (cubitainers) and acidified to $\mathrm{pH} \sim 2$ with ultra-clean $6 \mathrm{~N}$ hydrochloric acid $(\mathrm{Nd} \leq 1 \mathrm{ppt})$ within a few hours of collection.
Additionally, samples were collected from the trace metalclean, interconnected $2 \times 500 \mathrm{~L}$ tanks (made of fluorinated low density polyethylene, UCSC SAFe tanks) that were filled with seawater collected using trace metal-clean GO-FLO bottles 


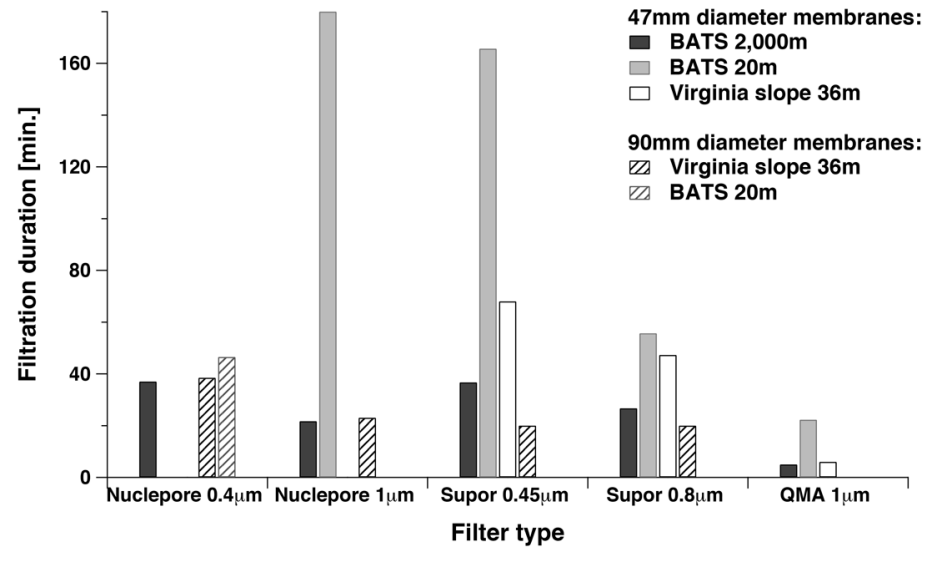

Fig. 2. Filtration duration for $10 \mathrm{~L}$ seawater from BATS and Virginia slope station filtered through different filter membranes and pressurizing the Niskin bottles using filtered, compressed air.

(Measures et al. 2008) for seawater from $2000 \mathrm{~m}$ water depth, and a trace metal-clean tow-fish (Geoffrey Smith, UCSC) for seawater from $15 \mathrm{~m}$ water depth, and filtered through an Osmonics cartridge filter with polycarbonate track-etched $0.2 \mu \mathrm{m}$ membrane. The water in the tanks was acidified to $\mathrm{pH} \sim 2$ with ultra-clean $6 \mathrm{~N}$ hydrochloric acid $(\mathrm{Nd} \leq 1 \mathrm{ppt})$ and homogenized for several hours using an all PFA Teflon diaphragm pump. These samples were used to compare Niskin and GO-FLO bottles and to test the effect of two different preconcentration methods on dissolved $\mathrm{Nd}$ isotopic composition and REE concentrations in seawater. The preconcentration methods that we tested are iron hydroxide coprecipitation and complexation with $\mathrm{HDEHP} / \mathrm{H}_{2} \mathrm{MEHP}$ using $\mathrm{C} 18$ cartridges (see below).

The samples collected for the baseline profiles ( 8 depths) were obtained from Niskin bottles and were filtered through Supor $0.45 \mu \mathrm{m}$ membrane filters (diameters $47 \mathrm{~mm}$ and 90 $\mathrm{mm}$ ) at BATS (10 L per sample), and AcroPak500 0.8/0.45 $\mu \mathrm{m}$ cartridges at SAFe (5 L per sample).

Before sampling, all sample containers, tubing, and filter holders were leached with ultra-clean or trace metal-clean 0.5$1 \mathrm{~N}$ hydrochloric acid for $2 \mathrm{~d}$ and thoroughly rinsed with ultra-pure water. Between sampling, the sample holders were rinsed with water, leached in trace-metal clean $\sim 1 \mathrm{~N}$ hydrochloric acid for at least a few hours, and rinsed with Milli-Q water. The tubing to connect the filter holders to the Niskin bottles was thoroughly rinsed with Milli-Q water between sampling.

\section{Preconcentration and isolation of $\mathrm{Nd}$ from seawater}

Using $10 \mathrm{~L}$ seawater samples from BATS $20 \mathrm{~m}$ and $2000 \mathrm{~m}$ onboard R/V Knorr, we performed two commonly used procedures to preconcentrate REEs from seawater: 1) iron hydroxide co-precipitation (e.g., Piepgras and Wasserburg 1980; Amakawa et al. 2004; Andersson et al. 2008), and 2) complexation with HDEHP/ $\mathrm{H}_{2} \mathrm{MEHP}$ using $\mathrm{C} 18$ cartridges ('C18 cartridge tests' hereafter) (Shabani et al. 1992; Jeandel et al. 1998; Lacan and Jeandel 2004a). Iron used for the Fe-hydroxide coprecipitation was cleaned by dissolving $\mathrm{FeCl}_{3}$ in $6 \mathrm{~N}$ hydrochloric acid and performing isopropyl ether back extraction (Dodson et al. 1936). We added $\sim 5 \mathrm{mg}$ cleaned Fe per liter of seawater to the samples that were previously acidified to $\mathrm{pH} \sim 2$. Following vigorous shaking of the samples and equilibration for at least 24 $\mathrm{h}$, ammonium hydroxide (Optima grade, $\mathrm{Nd} \leq 0.1 \mathrm{ppt}$ ) was added to raise the $\mathrm{pH}$ to 8.2-8.5. The samples were left for at least $48 \mathrm{~h}$ to allow the Fe-hydroxide precipitate to settle. All but 250-500 mL of the supernatant was then carefully siphoned off and discarded. To further separate the precipitate from the remaining supernatant and remove the salt, samples were centrifuged and washed three times with ultra-pure water, which was adjusted to a $\mathrm{pH}$ of $\sim 8$ with ammonium hydroxide (Optima grade, $\mathrm{Nd} \leq 1 \mathrm{ppt}$ ). This $\mathrm{pH}$ adjustment is important, as ultra-pure water has a slightly acidic $\mathrm{pH}$ and would hence redissolve some of the previously formed Fe-hydroxides. Back in the shore-based ultra-clean laboratory, the washed precipitate was dissolved in $2 \mathrm{~mL}$ of $1.5 \mathrm{~N}$ ultra-pure nitric acid. The iron was reduced by the addition of $1 \mathrm{~mL}$ of $0.9 \mathrm{~N}$ ascorbic acid, and the sample was passed through columns filled with Eichrom RE-Spec resin to remove the iron and the remaining sample matrix (Jones 2010). For REE analysis by multi- (MC) or single-collector inductively coupled plasma mass spectrometry (ICP-MS), no further purification was necessary. For Nd isotope analysis by thermal ionization mass spectrometry (TIMS), Nd was further isolated using $\alpha$-hydroxyisobutyric acid ( $\alpha$-HIBA) chemistry (Choppin and Silva 1956).

For preconcentration of $\mathrm{Nd}$ from seawater using C18 cartridges, a method initially proposed by Shabani et al. (1992), we followed the method of Jeandel et al. (1998) and Lacan and Jeandel (2004a). Briefly, C18 cartridges (Waters Corp., SepPak $^{\mathrm{TM}}$ classic C18 cartridge $\left.360 \mathrm{mg} 55-105 \mu \mathrm{m}\right)$ were loaded with $300 \mu \mathrm{L}$ phosphoric acid 2-ethylhexyl ester (HDEHP/ $\mathrm{H}_{2} \mathrm{MEHP}$ ) to three-quarters of the cartridge volume. For $10 \mathrm{~L}$ seawater, two cartridges that were connected in sequence using Kynar (polyvinylidene fluoride) barbed connectors, were used per sample. Seawater $\mathrm{pH}$ was adjusted to $\sim 3.5$ using ultra-clean ammonia hydroxide, and samples were pumped over the cartridges at $20 \mathrm{~mL} / \mathrm{min}$ using a peristaltic pump and Tygon tubing. In the shore-based ultra-clean laboratory, cartridges were washed with $5 \mathrm{~mL} 0.01 \mathrm{~N}$ hydrochloric acid to remove barium, and REEs were subsequently eluted with $35 \mathrm{~mL} 6 \mathrm{~N}$ hydrochloric acid. After taking the samples to dryness, the REEs were further purified using Eichrom TRU-Spec resin, and Nd was isolated using $\alpha$-HIBA chemistry. SAFe profile samples processed at Imperial College London were separated using Ln-Spec resin instead of $\alpha$-HIBA (e.g., Pin and Zalduegui 1997).

\section{Analysis of $\mathrm{Nd}$ isotopes}

Purified samples for $\mathrm{Nd}$ isotope analyses were loaded on single rhenium filaments with silica gel and analyzed as $\mathrm{NdO}^{+}$ on a VG Sector 54 thermal ionization mass spectrometer (TIMS) at Lamont-Doherty Earth Observatory of Columbia University (LDEO) and on a VG Sector TIMS at the University of Hawaii (UH). The total procedural blank for Nd using this 
procedure at $\mathrm{LDEO} / \mathrm{UH}$ is $3 \mathrm{pg}$. At Imperial College London, purified samples were loaded on single tungsten filaments with $\mathrm{TaCl}_{5}$ activator and analyzed as $\mathrm{NdO}^{+}$on a Thermo Scientific Triton TIMS. The total procedural blank using this procedure is $20 \mathrm{pg}$ (column chemistry and mass spectrometry blank: $<7 \mathrm{pg}$ ).

All $\mathrm{Nd}$ isotope ratios were normalized to ${ }^{146} \mathrm{Nd} /{ }^{144} \mathrm{Nd}=0.7219$ and are reported relative to a La Jolla of ${ }^{143} \mathrm{Nd} /{ }^{144} \mathrm{Nd}=0.511858$ (Lugmair et al. 1983) or a $\mathrm{JNd}_{\mathrm{i}}$ of 0.512115 (Tanaka et al. 2000). By convention, the ${ }^{143} \mathrm{Nd} /{ }^{144} \mathrm{Nd}$ ratios are expressed in $\varepsilon_{\mathrm{Nd}}$ notation: $\varepsilon_{\mathrm{Nd}}=\left[\left({ }^{143} \mathrm{Nd} /{ }^{144} \mathrm{Nd}_{\text {sample }} /{ }^{143} \mathrm{Nd} /{ }^{144} \mathrm{Nd}_{\mathrm{CHUR}}\right)-1\right] \times 10,000$, with a CHUR value of ${ }^{143} \mathrm{Nd} /{ }^{14}{ }^{4} \mathrm{Nd}_{\text {CHUR }}=0.512638$ (Jacobsen and Wasserburg 1980). The average La Jolla or $\mathrm{JNd}_{\mathrm{i}}{ }^{143} \mathrm{Nd} /{ }^{144} \mathrm{Nd}$ ratio for each analytical session is listed as footnote under the data tables.

Analysis of REE concentrations

For the analysis of REE concentrations at eight water depths at BATS, $50-100 \mathrm{~mL}$ aliquots of $10 \mathrm{~L}$ seawater samples were weighed and spiked with an REE spike that contains the isotopes ${ }^{142} \mathrm{Ce},{ }^{145} \mathrm{Nd},{ }^{149} \mathrm{Sm},{ }^{153} \mathrm{Eu},{ }^{155} \mathrm{Gd},{ }^{161} \mathrm{Dy},{ }^{167} \mathrm{Er}$, and ${ }^{171} \mathrm{Yb}$. The solution used was diluted from a mixed and calibrated spike provided by Prof. Gil Hanson of Stony Brook University. The samples were left to equilibrate with the spike for at least $24 \mathrm{~h}$ before addition of $\sim 600 \mu \mathrm{g}$ Fe. Ultra-clean ammonium hydroxide was used to raise the $\mathrm{pH}$ to $8-8.5$, and the samples were allowed to settle for $2 \mathrm{~d}$. The supernatant was then decanted and discarded and the Fe-hydroxide precipitate was concentrated by centrifugation and washed with $\mathrm{pH}$-adjusted ultra-clean water.

The REEs were subsequently isolated following the method of Jones (2010). Briefly, after reacting the samples with nitric acid and hydrofluoric acid to remove any hydrated silica, the samples were dissolved in $6 \mathrm{~N}$ nitric acid and $0.9 \mathrm{M}$ ascorbic acid and loaded onto $100 \mu \mathrm{L}$ columns containing 50-100 $\mu \mathrm{m}$ Eichrom RE-spec resin. Iron and major elements were washed with $4 \mathrm{~N}$ nitric acid and the REEs were eluted with $4 \mathrm{~N}$ hydrochloric acid. The samples were dissolved in 1-2 $\mathrm{mL}$ of $2 \%$ nitric acid in preparation for analysis.

The REE samples were analyzed on a VG Axiom multi-collector ICP-MS, using peak jumping on the axial multiplier in ion counting mode at LDEO. The MC-ICP-MS was equipped with a Cetac Aridus desolvating nebulizer that was used with a nitrogen-argon gas mixture to minimize oxide formation. The formation of oxides was monitored several times per day and the Ce oxide peaks were always between $0.015-0.008 \%$ of the primary peak. Nine procedural blanks were measured and yielded a maximum blank of less than $1.2 \%$ for all elements except for Ce (blank of 4.6\%). Blank corrections were carried out for all REE by subtracting the procedural blank from each sample.

The typical internal error was better than $2 \%$ and often better than $1 \%$, which includes the error magnification factors inherent to all isotope dilution measurements. External reproducibility for the isotope ratios measured for all the spikeenriched REEs was monitored with a spiked standard solution and was better than 3\% for all elements except Ce, which had an external error of $3.8 \%$.

For the analysis of Nd concentrations at BATS $20 \mathrm{~m}$ and Virginia slope station $36 \mathrm{~m}$, and eight depths at SAFe, $250 \mathrm{~mL}$ aliquots of $10 \mathrm{~L}$ ( $5 \mathrm{~L}$ at SAFe) seawater samples were weighed and spiked with a solution enriched in ${ }^{146} \mathrm{Nd}$. The spike was diluted and calibrated from a spike solution provided by Prof. John Mahoney (University of Hawaii at Manoa). The subsequent sample processing followed that described above. Neodymium concentrations were analyzed on a ThermoFinnigan Element 2 ICP-MS at UH. Procedural blanks had an Nd concentration of less than $0.6 \%$. The internal $2 \sigma$ standard error was better than 3\% (with one exception of $4 \%$ ) and typically less than $2 \%$. For the SAFe profile analyzed at Imperial College London (ICL), $5 \mathrm{~L}$ samples were spiked with ${ }^{150} \mathrm{Nd}$, pre-concentrated using C18 cartridges loaded with HDEHP/H $/ \mathrm{H}_{2} \mathrm{MEHP}$, separated using TRU Spec and Ln Spec chemistry, and analyzed for $\mathrm{Nd}$ isotope ratios and concentrations on a Thermo Scientific Triton TIMS.

\section{Assessment and discussion of filtration, sampling and preconcentration tests and GEOTRACES $\varepsilon_{N d}$ and REE baseline profiles at BATS and SAFe}

\section{Filter tests}

The Nd isotopic compositions obtained on seawater samples from BATS $20 \mathrm{~m}$, BATS $2000 \mathrm{~m}$, and Virginia slope station $36 \mathrm{~m}$ filtered using the different filter types and pore sizes described above, show good agreement for each station with $2 \sigma$ standard deviations of $56 \mathrm{ppm}$ (BATS $20 \mathrm{~m}, n=12$ ), 43 ppm (BATS 2000m, $n=13$ ), and 53 ppm (Virginia slope station 36 $\mathrm{m}, n=11$ ) (Table 2a, 2b, 2c, Fig. 3). Comparison of the individual $\varepsilon_{\mathrm{Nd}}$ results from the different stations reveals no systematic offsets among the different filter types and pore sizes. Furthermore, the obtained average $\mathrm{Nd}$ isotopic compositions at BATS $\left(20 \mathrm{~m}: \varepsilon_{\mathrm{Nd}}=-9.8 \pm 0.56,2000 \mathrm{~m}: \varepsilon_{\mathrm{Nd}}=-13.3 \pm 0.43\right)$ agree well with the average values and precision achieved by the international intercalibration at BATS $15 \mathrm{~m}\left(\varepsilon_{\mathrm{Nd}}=-9.2 \pm\right.$ $0.60,13$ labs $)$ and BATS $2000 \mathrm{~m}\left(\varepsilon_{\mathrm{Nd}}=-13.1 \pm 0.59,13\right.$ labs $)$ (van de Flierdt et al. 2012). The additional analysis of an 'unknown' Nd standard by participating labs also resulted in a similar $2 \sigma$ standard deviation of 56 ppm (13 labs, van de Flierdt et al. 2012). The close similarity between the precision of seawater samples that included extensive sample processing by the individual labs, using different preconcentration and ion chromatography methods, and the 'unknown' Nd standard that did not require any processing, led us to conclude that an inter-laboratory precision of around $\pm 0.6 \varepsilon_{\mathrm{Nd}}$ units is the best that can be achieved on samples of 5-15 $\mathrm{ng} \mathrm{Nd}$, and that the observed differences are due to analytical uncertainty rather than sample processing or matrix effects (van de Flierdt et al. 2012). The precision of our filter tests of $\pm 0.43-0.56 \varepsilon_{\mathrm{Nd}}$ units is therefore within the expected analytical uncertainty.

Similarly, the concentration of dissolved $\mathrm{Nd}$ measured on the same seawater samples at BATS $20 \mathrm{~m}$ and Virginia slope 
Table 2a: Filter tests at BATS $20 \mathrm{~m}$ water depth $\left(31^{\circ} 40^{\prime} \mathrm{N}, 6^{\circ}{ }^{\circ} 0^{\prime} \mathrm{W}\right)$

\begin{tabular}{|c|c|c|c|c|c|c|c|c|c|c|c|}
\hline filter type & $\begin{array}{l}\text { filter pore } \\
\text { size }[\mu \mathrm{m}]\end{array}$ & sample ID & $\begin{array}{c}\text { sample } \\
\text { volume }^{\mathrm{a}}\end{array}$ & $\begin{array}{c}{ }^{143} \mathrm{Nd} /{ }^{144} \mathrm{Nd} \\
\text { measured }\end{array}$ & $\begin{array}{l}\text { internal } \\
2 \sigma \mathrm{SE}\end{array}$ & $\begin{array}{l}{ }^{143} \mathrm{Nd} /{ }^{144} \mathrm{Nd} \\
\text { normalized }^{\mathrm{b}}\end{array}$ & $\varepsilon_{\mathrm{Nd}}{ }^{\mathrm{c}}$ & $\begin{array}{l}\text { internal } \\
2 \sigma \mathrm{SE}\end{array}$ & $\begin{array}{l}\text { external } \\
2 \sigma \mathrm{SD}^{\mathrm{d}}\end{array}$ & $\begin{array}{c}\mathrm{Nd} \\
{[\mathrm{ppt}]}\end{array}$ & $\begin{array}{l}\text { internal } \\
\% 2 \sigma \mathrm{SE}\end{array}$ \\
\hline \multicolumn{12}{|l|}{ BATS, 20m } \\
\hline Nuclepore & 0.4 & KN193-6-Nd-801 & $10 \mathrm{~L}, 0.25 \mathrm{~L}$ & 0.512091 & \pm 0.000013 & 0.512130 & $-9.9 \pm$ & \pm 0.3 & 0.3 & \multirow{2}{*}{\multicolumn{2}{|c|}{$2.0 \pm 2.5$}} \\
\hline Nuclepore & 0.4 & KN193-6-Nd-802 & $10 \mathrm{~L}$ & 0.512088 & \pm 0.000014 & 0.512127 & $-10.0 \pm$ & \pm 0.3 & 0.3 & & \\
\hline Nuclepore & 1 & KN193-6-Nd-805 & $10 \mathrm{~L}, 0.25 \mathrm{~L}$ & 0.512070 & \pm 0.000027 & 0.512109 & $-10.3 \pm$ & \pm 0.5 & 0.3 & \multirow{2}{*}{\multicolumn{2}{|c|}{$2.0 \pm 2.9$}} \\
\hline Nuclepore & 1 & KN193-6-Nd-806 & $10 \mathrm{~L}$ & 0.512082 & \pm 0.000018 & 0.512121 & $-10.1 \pm$ & \pm 0.4 & 0.3 & & \\
\hline Supor & 0.8 & KN193-6-Nd-811 & $10 \mathrm{~L}, 0.25 \mathrm{~L}$ & 0.512107 & \pm 0.000011 & 0.512147 & $-9.6 \pm$ & \pm 0.2 & 0.3 & \multirow{2}{*}{\multicolumn{2}{|c|}{$2.1 \pm 0.7$}} \\
\hline Supor & 0.8 & KN193-6-Nd-812 & $10 \mathrm{~L}$ & 0.512105 & \pm 0.000010 & 0.512144 & $-9.6 \pm$ & \pm 0.2 & 0.3 & & \\
\hline QMA & 1 & KN193-6-Nd-813 & $10 \mathrm{~L}, 0.25 \mathrm{~L}$ & 0.512103 & \pm 0.000012 & 0.512142 & $-9.7 \pm$ & \pm 0.2 & 0.3 & \multirow{2}{*}{\multicolumn{2}{|c|}{$2.1 \pm 4.1$}} \\
\hline QMA & 1 & KN193-6-Nd-814 & $10 \mathrm{~L}$ & 0.512119 & \pm 0.000011 & 0.512158 & $-9.4 \pm$ & \pm 0.2 & 0.3 & & \\
\hline Osmonics & 0.2 & KN193-6-Nd-817 & $10 \mathrm{~L}, 0.25 \mathrm{~L}$ & 0.512116 & \pm 0.000010 & 0.512155 & $-9.4 \pm$ & \pm 0.2 & 0.3 & \multirow{2}{*}{\multicolumn{2}{|c|}{$1.9 \pm 0.3$}} \\
\hline Osmonics & 0.2 & KN193-6-Nd-818 & $10 \mathrm{~L}$ & 0.512101 & \pm 0.000011 & 0.512140 & $-9.7 \pm$ & \pm 0.2 & 0.3 & & \\
\hline none & N/A & KN193-6-Nd-823 & $10 \mathrm{~L}, 0.25 \mathrm{~L}$ & 0.512097 & \pm 0.000015 & 0.512136 & $-9.8 \pm$ & \pm 0.3 & 0.3 & \multirow{2}{*}{\multicolumn{2}{|c|}{$2.1 \pm 1.7$}} \\
\hline none & N/A & KN193-6-Nd-824 & $10 \mathrm{~L}$ & 0.512085 & \pm 0.000013 & 0.512124 & $-10.0 \pm$ & \pm 0.3 & 0.3 & & \\
\hline & & & & & \multicolumn{2}{|c|}{ average BATS $20 \mathrm{~m}$} & -9.8 & & & \multicolumn{2}{|l|}{2.0} \\
\hline & & & & & \multicolumn{2}{|c|}{$2 \sigma \mathrm{SD}$} & 0.6 & & & \multicolumn{2}{|l|}{0.1} \\
\hline \multicolumn{12}{|c|}{ all samples analyzed at LDEO (VG Sector 54 TIMS). } \\
\hline \multicolumn{12}{|c|}{ a samples for isotope analyzes $=10 \mathrm{~L}$, for $\mathrm{Nd}$ concentrations $\sim 250 \mathrm{~mL}$. } \\
\hline \multirow{2}{*}{\multicolumn{12}{|c|}{$\begin{array}{l}{ }^{\mathrm{b}} \text { normalized to repeat analyses of La Jolla of }{ }^{143} \mathrm{Nd} /{ }^{144} \mathrm{Nd}=0.511820 \pm 0.000013(\mathrm{n}=9) \text {, relative to a La Jolla value of } 0.511858 \text { (Lugmair et al., } 1983 \text { ). } \\
{ }^{\mathrm{c}} \varepsilon_{\mathrm{Nd}} \text { values were calculated relative to a CHUR of } 0.512638 \text { (Jacobsen and Wasserburg, 1980). }\end{array}$}} \\
\hline & & & & & & & & & & & \\
\hline \multicolumn{12}{|c|}{ d external errors are derived from repeat standard analyses over the period of sample measurements; } \\
\hline
\end{tabular}

Table 2b: Filter tests at BATS $2,000 \mathrm{~m}$ water depth $\left(31^{\circ} 40^{\prime} \mathrm{N}, 64^{\circ} 10^{\prime} \mathrm{W}\right)$

\begin{tabular}{|c|c|c|c|c|c|c|c|c|c|}
\hline filter type & $\begin{array}{l}\text { filter pore } \\
\text { size }[\mu \mathrm{m}]\end{array}$ & sample ID & $\begin{array}{l}\text { sample } \\
\text { volume }\end{array}$ & $\begin{array}{c}{ }^{143} \mathrm{Nd} /{ }^{144} \mathrm{Nd} \\
\text { measured }\end{array}$ & $\begin{array}{l}\text { internal } \\
2 \sigma \mathrm{SE}\end{array}$ & $\begin{array}{l}{ }^{143} \mathrm{Nd} /{ }^{144} \mathrm{Nd} \\
\text { normalized }^{\mathrm{a}}\end{array}$ & $\varepsilon_{\mathrm{Nd}}^{\mathrm{b}}$ & $\begin{array}{l}\text { internal } \\
2 \sigma \mathrm{SE}\end{array}$ & $\begin{array}{l}\text { external } \\
2 \sigma \mathrm{SD}^{\mathrm{c}}\end{array}$ \\
\hline \multicolumn{10}{|c|}{ BATS, 2000m } \\
\hline Nuclepore & 0.4 & KN193-6-Nd-701 & $10 \mathrm{~L}$ & 0.511956 & \pm 0.000030 & 0.511963 & -13.2 & \pm 0.6 & 0.2 \\
\hline Nuclepore & 0.4 & KN193-6-Nd-702 & $10 \mathrm{~L}$ & 0.511948 & \pm 0.000018 & 0.511955 & -13.3 & \pm 0.4 & 0.2 \\
\hline Nuclepore & 1 & KN193-6-Nd-704 & $10 \mathrm{~L}$ & 0.511951 & \pm 0.000014 & 0.511958 & -13.3 & \pm 0.3 & 0.2 \\
\hline Nuclepore & 1 & KN193-6-Nd-706* & $10 \mathrm{~L}$ & 0.511937 & \pm 0.000012 & 0.511958 & -13.3 & \pm 0.2 & 0.3 \\
\hline Supor & 0.45 & KN193-6-Nd-707 & $10 \mathrm{~L}$ & 0.511939 & \pm 0.000016 & 0.511947 & -13.5 & \pm 0.3 & 0.2 \\
\hline Supor & 0.45 & KN193-6-Nd-708 & $10 \mathrm{~L}$ & 0.511953 & \pm 0.000012 & 0.511961 & -13.2 & \pm 0.2 & 0.2 \\
\hline Supor & 0.8 & KN193-6-Nd-710 & $10 \mathrm{~L}$ & 0.511958 & \pm 0.000012 & 0.511965 & -13.1 & \pm 0.2 & 0.2 \\
\hline Supor & 0.8 & KN193-6-Nd-711* & $10 \mathrm{~L}$ & 0.511941 & \pm 0.000007 & 0.511962 & -13.2 & \pm 0.1 & 0.3 \\
\hline QMA & 1 & KN193-6-Nd-713 & $10 \mathrm{~L}$ & 0.511947 & \pm 0.000014 & 0.511954 & -13.3 & \pm 0.3 & 0.2 \\
\hline Osmonics & 0.2 & KN193-6-Nd-719 & $10 \mathrm{~L}$ & 0.511919 & \pm 0.000018 & 0.511926 & -13.9 & \pm 0.4 & 0.2 \\
\hline Osmonics & 0.2 & KN193-6-Nd-720 & $10 \mathrm{~L}$ & 0.511953 & \pm 0.000020 & 0.511961 & -13.2 & \pm 0.4 & 0.2 \\
\hline none & N/A & KN193-6-Nd-716 & $10 \mathrm{~L}$ & 0.511955 & \pm 0.000012 & 0.511963 & -13.2 & \pm 0.2 & 0.2 \\
\hline \multirow[t]{3}{*}{ none } & N/A & KN193-6-Nd-717 & $10 \mathrm{~L}$ & 0.511934 & \pm 0.000015 & 0.511941 & -13.6 & \pm 0.3 & 0.2 \\
\hline & & & & & \multicolumn{2}{|c|}{ average BATS $2000 \mathrm{~m}$} & -13.3 & & \\
\hline & & & & & \multicolumn{2}{|c|}{$2 \sigma S D$} & 0.4 & & \\
\hline
\end{tabular}

all samples analyzed at LDEO (VG Sector 54 TIMS), except those marked with * that were analyzed at UH (VG Sector TIMS).

a normalized to repeat analyses of La Jolla of ${ }^{143} \mathrm{Nd} /{ }^{144} \mathrm{Nd}=0.511850 \pm 0.000011(\mathrm{n}=13)$, relative to a La Jolla value of 0.511858 .

For samples analyzed at UH (KN193-6-Nd-706, -711): La Jolla ${ }^{143} \mathrm{Nd} /{ }^{144} \mathrm{Nd}=0.511838 \pm 0.000015(\mathrm{n}=5)$

${ }^{\mathrm{b}} \varepsilon_{\mathrm{Nd}}$ values were calculated relative to a CHUR of 0.512638 (Jacobsen and Wasserburg, 1980).

${ }^{c}$ external errors are derived from repeat standard analyses over the period of sample measurements.

if internal errors are larger than external errors, these are plotted in Figure 3.

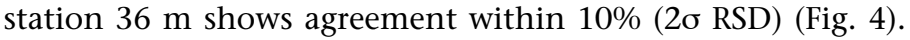
This is again similar to the uncertainty of the results achieved by the international intercalibration of REE concentrations for

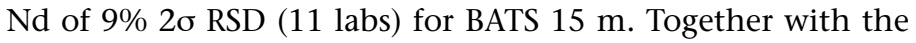

lack of any systematic differences in $\mathrm{Nd}$ isotopic composition or $\mathrm{Nd}$ concentration between filters when comparing the results from all three sampling locations, this suggests that the filter type and pore size of the most commonly used filters 
Table 2c: Filter tests at Virginia slope station $36 \mathrm{~m}$ water depth $\left(37^{\circ} 2^{\prime} \mathrm{N}, 47^{\circ} 24^{\prime} \mathrm{W}\right)$

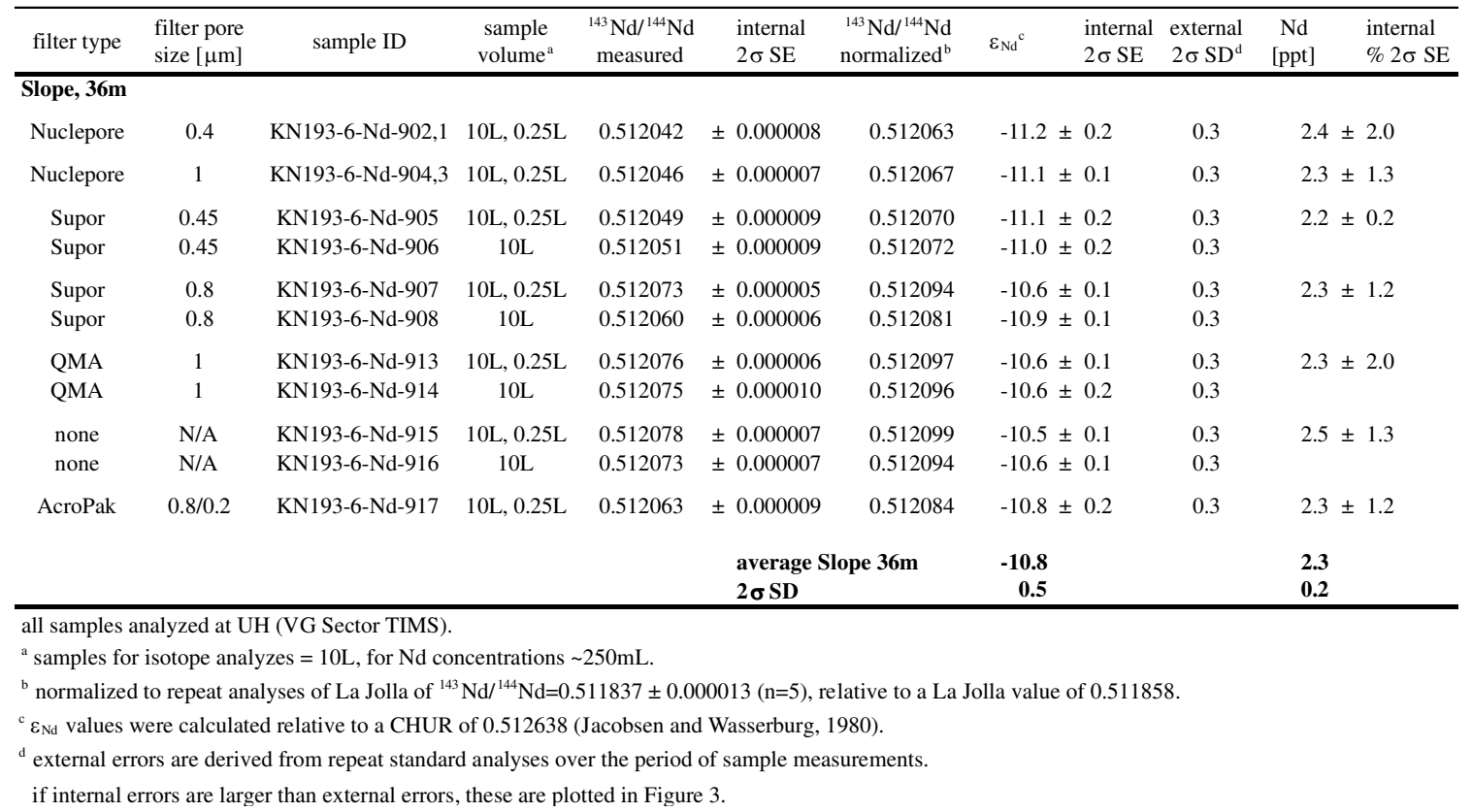

tested here do not affect the $\mathrm{Nd}$ isotopic composition or $\mathrm{Nd}$ concentration of seawater. Moreover, we did not observe a significant difference in $\mathrm{Nd}$ isotopic composition or concentration between filtered and unfiltered seawater (Figs. 3 and 4) either in the deep samples from BATS or the surface samples from BATS and the Virginia slope station, which have higher particle concentrations than deep water. We note, however, that suspended particles at the studied locations have a very similar $\mathrm{Nd}$ isotopic composition to ambient seawater (see below), making it difficult to rigorously assess the necessity of filtration and required filter type and pore-size on the dissolved $\mathrm{Nd}$ isotope ratios based on the results from the studied sites. We are aware of at least one sample from the near-bottom North Pacific, where the Nd isotopic composition of filtered seawater shows the influence of resuspended particles from the seafloor with a very different isotopic composition than would be realistically expected from bottom waters at that site (Amakawa et al. 2009). Therefore, despite the lack of evidence from this study that filtration of seawater for the analysis of dissolved $\mathrm{Nd}$ isotope ratios and concentrations is required, we strongly recommend filtration of seawater using filters of $\leq 0.45 \mu \mathrm{m}$ pore size in particular in areas where suspended particles are expected to have a different isotopic composition from local seawater and at stations and water depths with high particle concentrations, such as bottom or detached nepheloid layers, coastal regions, or areas of high aeolian or river input of particles.

\section{Preconcentration tests}

The comparison of two commonly used methods to preconcentrate REEs from seawater clearly shows that the use of iron hydroxide coprecipitation, and C18 cartridges loaded with $\mathrm{HDEHP} / \mathrm{H}_{2} \mathrm{MEHP}$ yield the same $\varepsilon_{\mathrm{Nd}}$ values with a 20_standard deviation of 37 ppm (BATS $2000 \mathrm{~m}$ and $20 \mathrm{~m}, n$ = 11) (Table 3, Fig. 5). Similarly, for the intercalibration of Nd isotopes (van de Flierdt et al. 2012), results from labs that used C18 cartridges for preconcentration compared well with those of labs that used iron hydroxide coprecipitation (Table 1 and Fig. 1 of van de Flierdt et al. 2012). As discussed by van de Flierdt et al. (2012), the only problem that may arise when using the Fe coprecipitation method is a high blank level of the Fe solution, which can, however, be addressed by thoroughly cleaning the Fe beforehand, using isopropyl ether back extraction (Dodson et al. 1936), as demonstrated by our total procedural blank of $3 \mathrm{pg}$ (see above).

\section{Standard Niskin versus trace metal-clean GO-FLO sampling bottles}

Comparison of $\varepsilon_{\mathrm{Nd}}$ values measured on water collected with two different water bottles, standard Niskin bottles and trace metal-clean GO-FLO bottles, yields the same values with an overall (BATS $2000 \mathrm{~m}$ and $20 \mathrm{~m}$ ) uncertainty of 43 ppm (2o_SD, $n=11$ ) (Table 3, Fig. 5). Neodymium concentrations measured on water collected with Niskin bottles (filter tests at BATS $20 \mathrm{~m}$ ) of $2.0 \pm 0.13 \mathrm{ppt}(n=6)$ (Table 2) also show good agreement with Nd concentrations of seawater collected with GO-FLO bottles from BATS $15 \mathrm{~m}$ that were measured as part of the international intercalibration of $\mathrm{Nd}$ isotopes and REE concentrations $(2.0 \pm 0.19 \mathrm{ppt}$, mean of results from 11 different labs; van de Flierdt et al. 2012). All other REE concentrations measured on seawater collected with standard Niskin bottles (BATS profile samples) and trace metal-clean GO-FLO bottles (intercalibration samples measured by LDEO, van de Flierdt et al. 2012) also

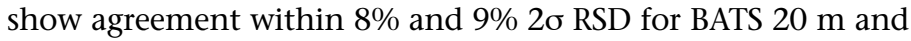



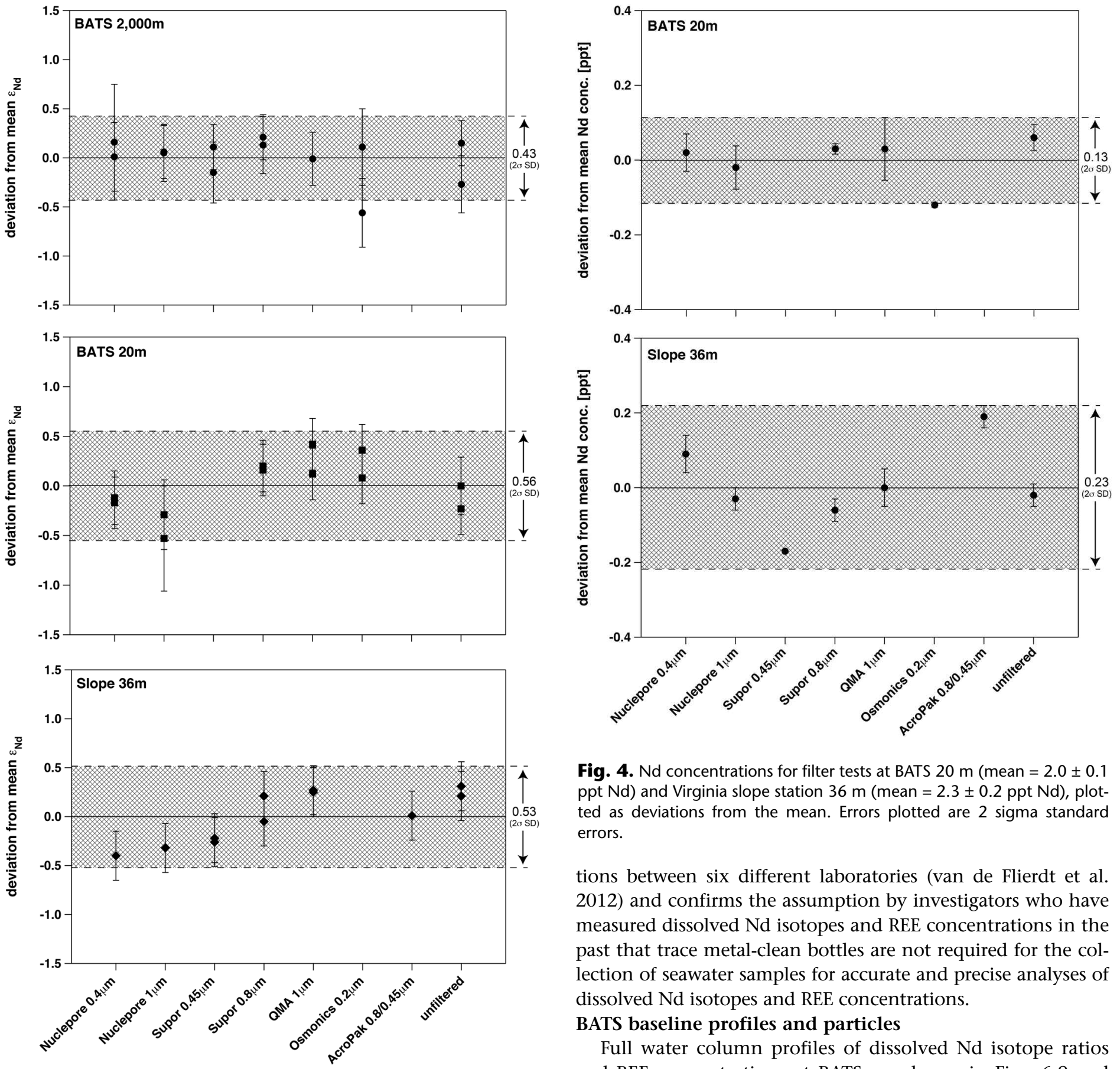

Fig. 4. $\mathrm{Nd}$ concentrations for filter tests at BATS $20 \mathrm{~m}$ (mean $=2.0 \pm 0.1$ ppt Nd) and Virginia slope station $36 \mathrm{~m}$ (mean $=2.3 \pm 0.2$ ppt Nd), plotted as deviations from the mean. Errors plotted are 2 sigma standard errors.

tions between six different laboratories (van de Flierdt et al. 2012) and confirms the assumption by investigators who have measured dissolved $\mathrm{Nd}$ isotopes and REE concentrations in the past that trace metal-clean bottles are not required for the collection of seawater samples for accurate and precise analyses of dissolved $\mathrm{Nd}$ isotopes and REE concentrations.

BATS baseline profiles and particles

Full water column profiles of dissolved $\mathrm{Nd}$ isotope ratios and REE concentrations at BATS are shown in Figs. 6-9 and

Fig. 3. $\mathrm{Nd}$ isotope ratios in $\varepsilon_{\mathrm{Nd}}$ notation plotted as deviations from the mean for the filter tests at BATS $2000 \mathrm{~m}$ (mean $\varepsilon_{\mathrm{Nd}}=-13.3 \pm 0.4$ ), BATS $20 \mathrm{~m}$ (mean $\varepsilon_{\mathrm{Nd}}=-9.8 \pm 0.6$ ), and Virginia slope station (mean $\varepsilon_{\mathrm{Nd}}=$ $-10.8 \pm 0.5)$. Errors plotted are external two sigma standard deviations. In cases where the internal two sigma standard error of an individual analysis was larger, this error was plotted.

$2000 \mathrm{~m}$, respectively. Cerium concentrations show slightly higher deviations of 13\% and 14\% 2o RSD at BATS $20 \mathrm{~m}$ and $2000 \mathrm{~m}$, respectively. This is within the uncertainty observed in the international intercalibration of dissolved REE concentradocumented in Tables 4 and 5. The $\mathrm{Nd}$ isotopic composition at BATS is highest at the surface with an $\varepsilon_{\mathrm{Nd}}$ value of -9.3 at 20 m (Fig. 6), similar to that reported by Piepgras and Wasserburg (1980) from a station southwest of BATS (OCE63 Station 1, $27^{\circ} \mathrm{N}, 74^{\circ} 20^{\prime} \mathrm{W}$, Fig. 7). The depth interval 75-500 $\mathrm{m}$ at BATS shows a constant isotopic composition of $\varepsilon_{\mathrm{Nd}}=-10.1$. Values below that depth decrease to $\varepsilon_{\mathrm{Nd}}=-13.3$ at $1000 \mathrm{~m}$ water depth, followed by a small gradual increase to -12.5 at 3000 $\mathrm{m}$, and a constant $\varepsilon_{\mathrm{Nd}}$ of -12.5 to -12.6 from $3000 \mathrm{~m}$ to 4500 $\mathrm{m}$ water depth (Fig. 6). 
Table 3: Sampling and preconcentration tests at BATS

Preconcentration tests: $\mathbf{C 1 8}$ cartridge vs. Fe co-precipitation

\begin{tabular}{|c|c|c|c|c|c|c|c|c|c|c|}
\hline $\begin{array}{l}\text { preconc. } \\
\text { method }\end{array}$ & filter type ${ }^{a}$ & sample ID & $\begin{array}{l}\text { sample } \\
\text { volume }\end{array}$ & $\begin{array}{c}{ }^{143} \mathrm{Nd} /{ }^{144} \mathrm{Nd} \\
\text { measured }\end{array}$ & & $\begin{array}{l}\text { internal } \\
2 \sigma \mathrm{SE}\end{array}$ & $\begin{array}{r}{ }^{143} \mathrm{Nd} /{ }^{144} \mathrm{Nd} \\
\text { normalized }^{\mathrm{b}}\end{array}$ & $\varepsilon_{\mathrm{Nd}}^{\mathrm{c}}$ & $\begin{array}{l}\text { internal } \\
2 \sigma \mathrm{SE}\end{array}$ & $\begin{array}{l}\text { external } \\
2 \sigma \mathrm{SD}^{\mathrm{d}}\end{array}$ \\
\hline \multicolumn{11}{|l|}{ BATS, 20m } \\
\hline Fe co-precip. & Osmonics $0.2 \mu \mathrm{m}$ & KN193-6-Nd-609 & $10 \mathrm{~L}$ & 0.512108 & \pm & 0.000014 & 0.512147 & -9.6 & \pm 0.3 & 0.3 \\
\hline Fe co-precip. & Osmonics $0.2 \mu \mathrm{m}$ & KN193-6-Nd-526 & $10 \mathrm{~L}$ & 0.512149 & \pm & 0.000008 & 0.512162 & -9.3 & \pm 0.2 & 0.4 \\
\hline Fe co-precip. & Osmonics $0.2 \mu \mathrm{m}$ & KN193-6-Nd-527 & $10 \mathrm{~L}$ & 0.512132 & \pm & 0.000011 & 0.512145 & -9.6 & \pm 0.2 & 0.4 \\
\hline C18 cartridge & Osmonics $0.2 \mu \mathrm{m}$ & KN193-6-Nd-612 & $10 \mathrm{~L}$ & 0.512119 & \pm & 0.000010 & 0.512158 & -9.4 & \pm 0.2 & 0.4 \\
\hline \multirow[t]{3}{*}{ C18 cartridge } & Osmonics $0.2 \mu \mathrm{m}$ & KN193-6-Nd-613 & $10 \mathrm{~L}$ & 0.512146 & \pm & 0.000015 & 0.512152 & -9.5 & \pm 0.3 & 0.3 \\
\hline & & & & & & \multicolumn{2}{|c|}{ average BATS $20 \mathrm{~m}$} & -9.5 & & \\
\hline & & & & & & \multicolumn{2}{|c|}{$2 \sigma \mathrm{SD}$} & 0.3 & & \\
\hline \multicolumn{11}{|l|}{ BATS, 2000m } \\
\hline Fe co-precip. & Osmonics $0.2 \mu \mathrm{m}$ & KN193-6-Nd-412 & $10 \mathrm{~L}$ & 0.511905 & \pm & 0.000010 & 0.511944 & -13.5 & \pm 0.2 & 0.3 \\
\hline Fe co-precip. & Osmonics $0.2 \mu \mathrm{m}$ & KN193-6-Nd-413 & $10 \mathrm{~L}$ & 0.511922 & \pm & 0.000010 & 0.511961 & -13.2 & \pm 0.2 & 0.3 \\
\hline Fe co-precip. & Osmonics $0.2 \mu \mathrm{m}$ & KN193-6-Nd-323 & $10 \mathrm{~L}$ & 0.511941 & \pm & 0.000008 & 0.511954 & -13.3 & \pm 0.2 & 0.4 \\
\hline Fe co-precip. & Osmonics $0.2 \mu \mathrm{m}$ & KN193-6-Nd-324 & $10 \mathrm{~L}$ & 0.511943 & \pm & 0.000015 & 0.511956 & -13.3 & \pm 0.3 & 0.4 \\
\hline C18 cartridge & Osmonics $0.2 \mu \mathrm{m}$ & KN193-6-Nd-414 & $10 \mathrm{~L}$ & 0.511963 & \pm & 0.000019 & 0.511969 & -13.0 & \pm 0.4 & 0.3 \\
\hline C18 cartridge* & Osmonics $0.2 \mu \mathrm{m}$ & KN193-6-Nd-415 & $10 \mathrm{~L}$ & 0.511856 & \pm & 0.000011 & 0.511895 & -14.5 & \pm 0.2 & 0.4 \\
\hline \multirow[t]{3}{*}{ C18 cartridge } & Osmonics $0.2 \mu \mathrm{m}$ & KN193-6-Nd-416 & $10 \mathrm{~L}$ & 0.511938 & \pm & 0.000009 & 0.511977 & -12.9 & \pm 0.2 & 0.4 \\
\hline & & & & & & \multicolumn{2}{|c|}{ average BATS $2000 \mathrm{~m}$} & -13.2 & & \\
\hline & & & & & & \multicolumn{2}{|c|}{$2 \sigma \mathrm{SD}$} & 0.5 & & \\
\hline
\end{tabular}

Sampling tests: Niskin vs. GO-GLO bottles

\begin{tabular}{|c|c|c|c|c|c|c|c|c|c|c|}
\hline $\begin{array}{l}\text { preconc. } \\
\text { method }\end{array}$ & filter type ${ }^{a}$ & sample ID & $\begin{array}{l}\text { sample } \\
\text { volume }\end{array}$ & $\begin{array}{c}{ }^{143} \mathrm{Nd} /{ }^{144} \mathrm{Nd} \\
\text { measured }\end{array}$ & & $\begin{array}{l}\text { internal } \\
2 \sigma \mathrm{SE}\end{array}$ & $\begin{array}{r}{ }^{143} \mathrm{Nd} /{ }^{144} \mathrm{Nd} \\
\text { normalized }^{\mathrm{b}}\end{array}$ & $\varepsilon_{\mathrm{Nd}}^{\mathrm{c}}$ & $\begin{array}{l}\text { internal } \\
2 \sigma \mathrm{SE}\end{array}$ & $\begin{array}{l}\text { external } \\
2 \sigma \mathrm{SD}^{\mathrm{C}}\end{array}$ \\
\hline \multicolumn{11}{|l|}{ BATS, 20m } \\
\hline Niskin & Osmonics $0.2 \mu \mathrm{m}$ & KN193-6-Nd-817 & $10 \mathrm{~L}$ & 0.512116 & \pm & 0.000010 & 0.512157 & -9.4 & \pm 0.2 & 0.3 \\
\hline Niskin & Osmonics $0.2 \mu \mathrm{m}$ & KN193-6-Nd-818 & $10 \mathrm{~L}$ & 0.512101 & \pm & 0.000011 & 0.512143 & -9.7 & \pm 0.2 & 0.3 \\
\hline GO-FLO & Osmonics $0.2 \mu \mathrm{m}$ & KN193-6-Nd-609 & $10 \mathrm{~L}$ & 0.512108 & \pm & 0.000014 & 0.512147 & -9.6 & \pm 0.3 & 0.3 \\
\hline GO-FLO & Osmonics $0.2 \mu \mathrm{m}$ & KN193-6-Nd-526 & $10 \mathrm{~L}$ & 0.512149 & \pm & 0.000008 & 0.512162 & -9.3 & \pm 0.2 & 0.4 \\
\hline \multirow[t]{3}{*}{ GO-FLO } & Osmonics $0.2 \mu \mathrm{m}$ & KN193-6-Nd-527 & $10 \mathrm{~L}$ & 0.512132 & \pm & 0.000011 & 0.512145 & -9.6 & \pm 0.2 & 0.4 \\
\hline & & & & & & \multicolumn{2}{|c|}{ average BATS $20 \mathrm{~m}$} & -9.5 & & \\
\hline & & & & & & \multicolumn{2}{|l|}{$2 \sigma \mathrm{SD}$} & 0.3 & & \\
\hline \multicolumn{11}{|c|}{ BATS, 2000m } \\
\hline Niskin & Osmonics $0.2 \mu \mathrm{m}$ & KN193-6-Nd-719 & $10 \mathrm{~L}$ & 0.511919 & \pm & 0.000018 & 0.511926 & -13.9 & \pm 0.4 & 0.2 \\
\hline Niskin & Osmonics $0.2 \mu \mathrm{m}$ & KN193-6-Nd-720 & $10 \mathrm{~L}$ & 0.511953 & \pm & 0.000020 & 0.511961 & -13.2 & \pm 0.4 & 0.2 \\
\hline GO-FLO & Osmonics $0.2 \mu \mathrm{m}$ & KN193-6-Nd-412 & $10 \mathrm{~L}$ & 0.511905 & \pm & 0.000010 & 0.511944 & -13.5 & \pm 0.2 & 0.3 \\
\hline GO-FLO & Osmonics $0.2 \mu \mathrm{m}$ & KN193-6-Nd-413 & $10 \mathrm{~L}$ & 0.511922 & \pm & 0.000010 & 0.511961 & -13.2 & \pm 0.2 & 0.3 \\
\hline GO-FLO & Osmonics $0.2 \mu \mathrm{m}$ & KN193-6-Nd-323 & $10 \mathrm{~L}$ & 0.511941 & \pm & 0.000008 & 0.511954 & -13.3 & \pm 0.2 & 0.4 \\
\hline \multirow[t]{3}{*}{ GO-FLO } & Osmonics $0.2 \mu \mathrm{m}$ & KN193-6-Nd-324 & $10 \mathrm{~L}$ & 0.511943 & \pm & 0.000015 & 0.511956 & -13.3 & \pm 0.3 & 0.4 \\
\hline & & & & & & \multicolumn{2}{|c|}{ average BATS $2000 \mathrm{~m}$} & -13.4 & & \\
\hline & & & & & & \multicolumn{2}{|c|}{$2 \sigma \mathrm{SD}$} & 0.5 & & \\
\hline
\end{tabular}

all analyzed at LDEO (VG Sector 54 TIMS).

${ }^{a}$ collected from trace metal-clean 2 x 500L tanks.

${ }^{\mathrm{b}} \mathrm{KN} 193-6-415,416,612$ : normalized to repeat analyses of JNdi of ${ }^{143} \mathrm{Nd} /{ }^{144} \mathrm{Nd}=0.51208 \pm 0.000021(\mathrm{n}=6)$ relatice to a $\mathrm{JNd}_{\mathrm{i}}$ value of 0.512115 (Tanaka et al., 2000).

KN193-6-323, 324, 526, 527: normalized to repeat analyses of La Jolla of ${ }^{143} \mathrm{Nd} /{ }^{144} \mathrm{Nd}=0.511845 \pm 0.000021(\mathrm{n}=10)$, relative to a La Jolla value of 0.511858 (Lugmair et al, 1983).

all other samples: normalized to repeat analyses of La Jolla of ${ }^{143} \mathrm{Nd} /{ }^{144} \mathrm{Nd}=0.51185 \pm 0.000011(\mathrm{n}=13)$, relative to a La Jolla value of 0.511858 (Lugmair et al, 1983).

${ }^{\mathrm{c}} \varepsilon_{\mathrm{Nd}}$ values were calculated relative to a CHUR of 0.512638 (Jacobsen and Wasserburg, 1980).

d external errors are derived from repeat standard analyses over the period of sample measurements;

if internal errors are larger than external errors, these are plotted

$*$ excluded from calculation of mean and $2 \sigma$ standard deviation

The hydrography at BATS shows a similar profile with constant salinity of 36.5-36.6 psu and potential temperature of $17-20^{\circ} \mathrm{C}$ in the upper $\sim 70-500 \mathrm{~m}$, and a rapid salinity and temperature decrease toward $1000 \mathrm{~m}$ water depth (Fig. 6) (KN193- 

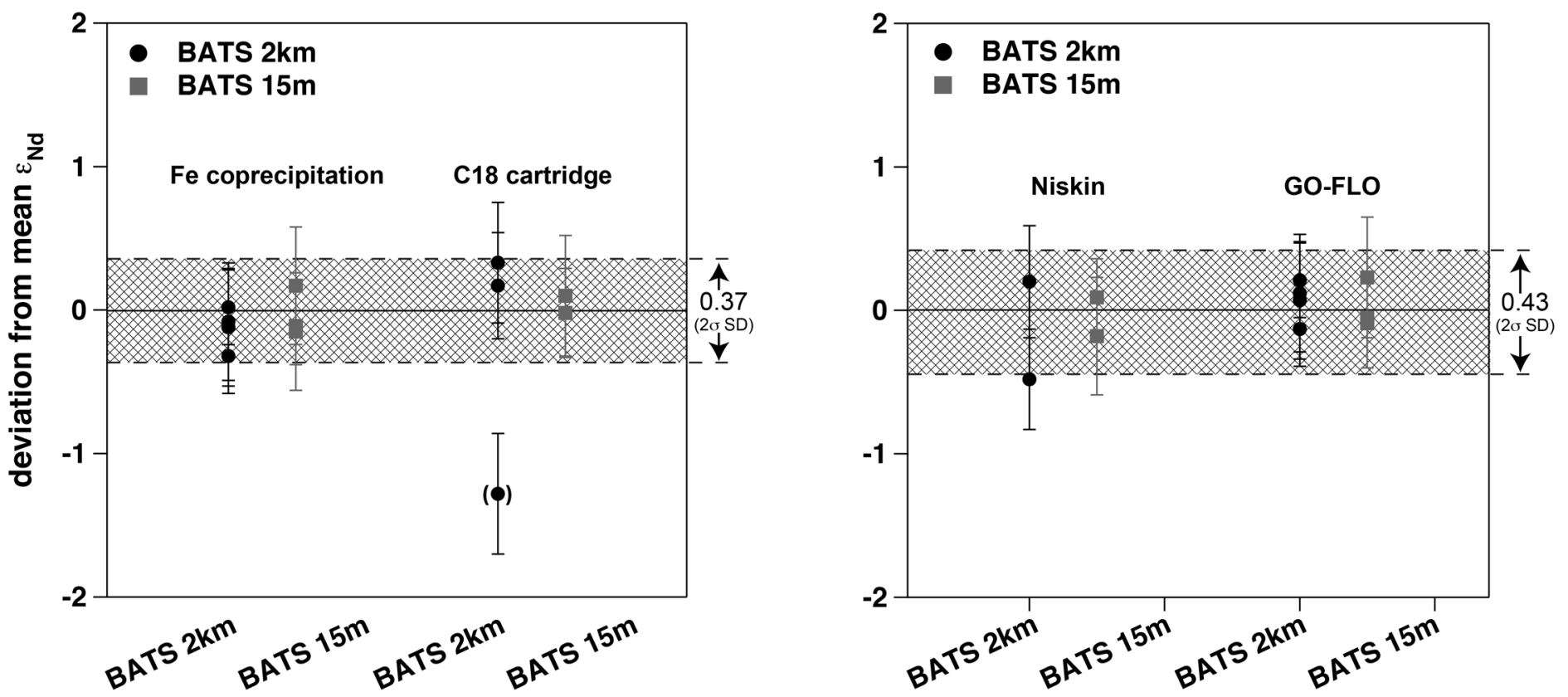

Fig. 5. Nd isotope ratios in $\varepsilon_{\mathrm{Nd}}$ notation at BATS $15 \mathrm{~m}$ and $2000 \mathrm{~m}$ plotted as deviations from the mean for the preconcentration tests (Fe coprecipitation compared with C18 cartridges; BATS $2000 \mathrm{~m}$ : mean $\varepsilon_{\mathrm{Nd}}=-13.2 \pm 0.5$, BATS $15 \mathrm{~m}$ : mean $\varepsilon_{\mathrm{Nd}}=-9.5 \pm 0.3$ ), and sampling bottle tests (standard Niskin bottles compared to trace metal-clean GO-FLO bottles; BATS $2000 \mathrm{~m}$ : mean $\varepsilon_{\mathrm{Nd}}=-13.4 \pm 0.5$, BATS $15 \mathrm{~m}$ : mean $\varepsilon_{\mathrm{Nd}}=-9.5 \pm 0.3$ ). One value from the $\mathrm{C} 18$ cartridge test was excluded from the calculation of the mean and standard deviation. Errors plotted are external two sigma standard deviations. In cases where the internal two sigma standard error of an individual analysis was larger, this error was plotted.

\section{Table 4: $\mathrm{Nd}$ isotope ratio and concentration baseline profiles at BATS $\left(31^{\circ} 45.62^{\prime} \mathrm{N}, 6^{\circ} 6.02^{\prime} \mathrm{W}\right)$}

\begin{tabular}{|c|c|c|c|c|c|c|c|c|c|c|c|c|c|c|}
\hline sample ID & $\begin{array}{c}\text { water } \\
\text { depth [m] }\end{array}$ & $\begin{array}{l}\text { sigma-t } \\
{\left[\mathrm{kg} / \mathrm{m}^{3}\right]}\end{array}$ & $\begin{array}{c}\text { pot. Temp. } \\
{\left[{ }^{\circ} \mathrm{C}\right]}\end{array}$ & Salinity & filter type & $\begin{array}{l}\text { filter diameter } \\
{[\mathrm{mm}]}\end{array}$ & $\begin{array}{l}\text { sample } \\
\text { volume }\end{array}$ & $\begin{array}{l}{ }^{143} \mathrm{Nd} /{ }^{144} \mathrm{Nd} \\
\text { normalized }^{\mathrm{a}}\end{array}$ & \pm & $\begin{array}{l}\text { internal } \\
2 \sigma \mathrm{SE}\end{array}$ & $\varepsilon_{\mathrm{Nd}}^{\mathrm{b}}$ & \pm & $\begin{array}{l}\text { internal } \\
2 \sigma \mathrm{SE}\end{array}$ & $\begin{array}{l}\text { external } \\
2 \sigma \mathrm{SD}^{c}\end{array}$ \\
\hline KN193-6-Nd-Th-022 & 20 & 24.980 & 23.366 & 36.518 & Supor $0.45 \mu \mathrm{m}$ & 90 & $10 \mathrm{~L}$ & 0.512165 & \pm & 0.000010 & -9.2 & \pm & 0.2 & 0.2 \\
\hline KN193-6-Nd-Th-019 & 75 & 26.013 & 19.848 & 36.586 & Supor $0.45 \mu \mathrm{m}$ & 90 & $10 \mathrm{~L}$ & 0.512120 & \pm & 0.000012 & -10.1 & \pm & 0.2 & 0.3 \\
\hline KN193-6-Nd-Th-016 & 500 & 26.588 & 16.855 & 36.353 & Supor $0.45 \mu \mathrm{m}$ & 47 & $10 \mathrm{~L}$ & 0.512118 & \pm & 0.000011 & -10.1 & \pm & 0.2 & 0.2 \\
\hline KN193-6-Nd-Th-013 & 1000 & 27.550 & 6.414 & 35.065 & Supor $0.45 \mu \mathrm{m}$ & 47 & $10 \mathrm{~L}$ & 0.511957 & \pm & 0.000009 & -13.3 & \pm & 0.2 & 0.3 \\
\hline KN193-6-Nd-Th-010 & 2000 & 27.810 & 3.493 & 34.964 & Supor $0.45 \mu \mathrm{m}$ & 47 & $10 \mathrm{~L}$ & 0.511967 & \pm & 0.000010 & -13.1 & \pm & 0.2 & 0.3 \\
\hline KN193-6-Nd-Th-007 & 3000 & 27.872 & 2.506 & 34.927 & Supor $0.45 \mu \mathrm{m}$ & 47 & $10 \mathrm{~L}$ & 0.511999 & \pm & 0.000011 & -12.5 & \pm & 0.2 & 0.3 \\
\hline KN193-6-Nd-Th-004 & 3750 & 27.891 & 1.949 & 34.894 & Supor $0.45 \mu \mathrm{m}$ & 47 & $10 \mathrm{~L}$ & 0.511994 & \pm & 0.000012 & -12.6 & \pm & 0.2 & 0.3 \\
\hline KN193-6-Nd-Th-001 & 4500 & 27.891 & 1.815 & 34.881 & Supor $0.45 \mu \mathrm{m}$ & 47 & $10 \mathrm{~L}$ & 0.511994 & \pm & 0.000013 & -12.6 & \pm & 0.3 & 0.3 \\
\hline
\end{tabular}

${ }^{\text {a }}$ normalized to repeat analyses of La Jolla, relative to a La Jolla value of 0.51186 .

${ }^{\mathrm{b}} \varepsilon_{\mathrm{Nd}}$ values were calculated relative to a CHUR of 0.512638 (Jacobsen and Wasserburg, 1980).

${ }^{c}$ external errors are derived from repeat standard analyses over the period of sample measurements;

if internal errors are larger than external errors, these are plotted in Figure 6

6 CTD data: Table 4). Below $1000 \mathrm{~m}$, salinity and temperature gradually decrease toward the bottom. The constant temperature-salinity properties in the upper $\sim 70-500 \mathrm{~m}$ (Figs. $1 \mathrm{~b}$ and 6) mark the position of Subtropical Mode Water (STMW, 'Eighteen-Degree Water' of Worthington 1959) that is formed south of the Gulf Stream extension at $\sim 65^{\circ} \mathrm{N}$ (Worthington 1959; McCartney 1982; Hanawa and Talley 2001). The constant Nd isotopic composition of $\varepsilon_{\mathrm{Nd}}=-10.1$ over the depth range of STMW is consistent with the characteristic vertical homogeneity of STMW properties and supports the validity of $\varepsilon_{\mathrm{Nd}}$ as a water mass tracer even at shallow water depth. The same constant Nd isotope ratios of STMW have been reported by Piepgras and Wasserburg (1987) from a station further north of BATS $\left(\varepsilon_{\mathrm{Nd}}=-10.5\right.$; AII-109-1-Station $30,36^{\circ} 15^{\prime} \_\mathrm{N}, 61^{\circ} 58^{\prime} \mathrm{W}$; Fig. 7).

The water below the STMW layer at BATS shows a small but well-defined silicate maximum that marks the depth of AAIW (e.g., Tsuchiya 1989), which is underlain by NADW (Figs. 1b and 6). The $\mathrm{Nd}$ isotope ratio at $1000 \mathrm{~m}$ water depth of $\varepsilon_{\mathrm{Nd}}=$ -13.3 shows no influence of the typical $\varepsilon_{\mathrm{Nd}}$ signature of AAIW in the South Atlantic $\left(\varepsilon_{\mathrm{Nd}}=-9\right.$ to -8 , Jeandel 1993). Other intermediate water $\varepsilon_{\mathrm{Nd}}$ data available from the West Atlantic 

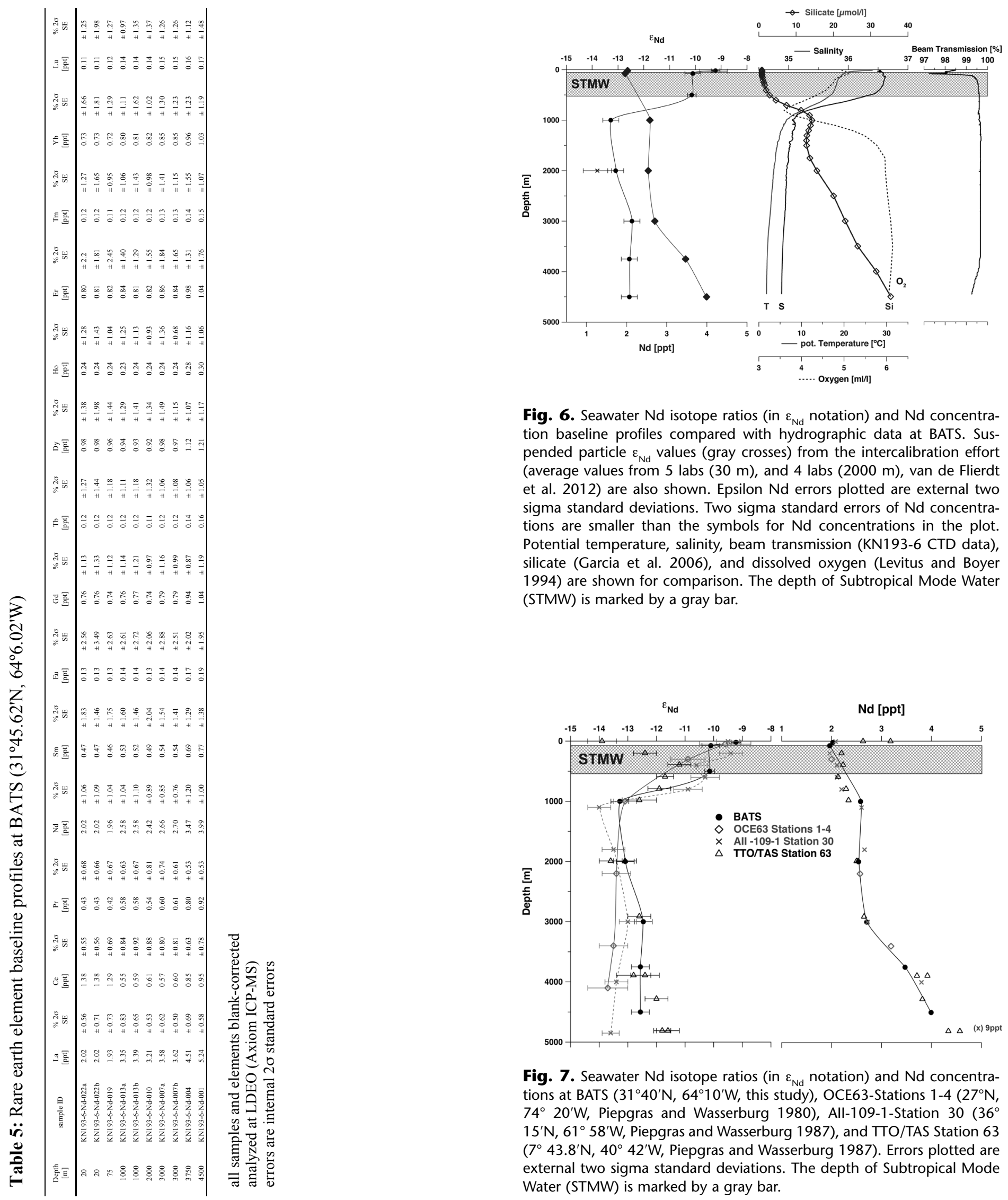

Fig. 6. Seawater $\mathrm{Nd}$ isotope ratios (in $\varepsilon_{\mathrm{Nd}}$ notation) and $\mathrm{Nd}$ concentration baseline profiles compared with hydrographic data at BATS. Suspended particle $\varepsilon_{\mathrm{Nd}}$ values (gray crosses) from the intercalibration effort (average values from 5 labs $(30 \mathrm{~m})$, and 4 labs $(2000 \mathrm{~m})$, van de Flierdt et al. 2012) are also shown. Epsilon Nd errors plotted are external two sigma standard deviations. Two sigma standard errors of $\mathrm{Nd}$ concentrations are smaller than the symbols for $\mathrm{Nd}$ concentrations in the plot. Potential temperature, salinity, beam transmission (KN193-6 CTD data), silicate (Garcia et al. 2006), and dissolved oxygen (Levitus and Boyer 1994) are shown for comparison. The depth of Subtropical Mode Water (STMW) is marked by a gray bar.

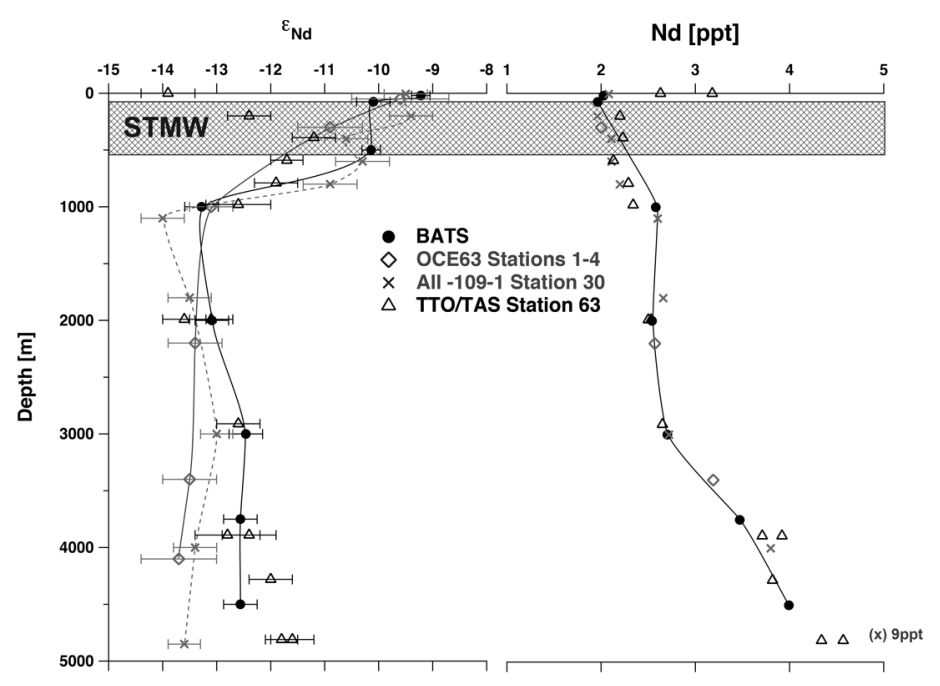

Fig. 7. Seawater $\mathrm{Nd}$ isotope ratios (in $\varepsilon_{\mathrm{Nd}}$ notation) and $\mathrm{Nd}$ concentrations at BATS $\left(31^{\circ} 40^{\prime} \mathrm{N}, 64^{\circ} 10^{\prime} \mathrm{W}\right.$, this study), OCE63-Stations $1-4\left(27^{\circ} \mathrm{N}\right.$, $74^{\circ} 20^{\prime} \mathrm{W}$, Piepgras and Wasserburg 1980), All-109-1-Station 30 (36 $15^{\prime} \mathrm{N}, 61^{\circ} 58^{\prime} \mathrm{W}$, Piepgras and Wasserburg 1987), and TTO/TAS Station 63 $\left(7^{\circ} 43.8^{\prime} \mathrm{N}, 40^{\circ} 42^{\prime} \mathrm{W}\right.$, Piepgras and Wasserburg 1987). Errors plotted are external two sigma standard deviations. The depth of Subtropical Mode Water (STMW) is marked by a gray bar. 
$\left(36^{\circ} \mathrm{N}: \varepsilon_{\mathrm{Nd}}=-14 ; 7^{\circ} \mathrm{N}: \varepsilon_{\mathrm{Nd}}=-12.6\right.$, Piepgras and Wasserburg $1987)$, however, indicate a slight trend from higher values in the south to lower values in the north (Fig. 7). This could suggest that the more radiogenic $\varepsilon_{\mathrm{Nd}}$ signature of AAIW, similar to its characteristic salinity minimum, is degraded or lost at this latitude through mixing with less radiogenic North Atlantic water masses (Fig. 6). The rapid change to lower $\varepsilon_{\mathrm{Nd}}$ at $1000 \mathrm{~m}$ water depth clearly marks the transition to underlying Upper$\operatorname{NADW}\left(\varepsilon_{\mathrm{Nd}} \sim-13.5\right.$, Lacan and Jeandel 2005). The change to higher $\varepsilon_{\mathrm{Nd}}$ near $3000 \mathrm{~m}$ water depth $\left(\varepsilon_{\mathrm{Nd}}=-12.5\right)$ is consistent with a change to Middle and Lower NADW (Lacan and Jeandel 2005), and the increasing influence of more radiogenic Antarctic Bottom Water (AABW) below 3000 m, as suggested by increasing phosphate and silicate concentrations (Fig. 6).

Neodymium isotope ratios of suspended particles from the sub-surface at BATS (30 m, QMA $1 \mu \mathrm{m}$ double filters) and 2000 $\mathrm{m}$ water depth (Supor $0.45 \mu \mathrm{m}$ filters) were measured as part of the international intercalibration effort (van de Flierdt et al. 2012). The surface particles were leached from the filter with $0.6 \mathrm{~N}$ hydrochloric acid at $60^{\circ} \mathrm{C}$ for $20 \mathrm{~h}$ following the method of Jeandel et al. (1995), and the deep particles were subjected to a total digest by three laboratories following the method of Cullen and Sherrell (1999), while one lab leached the deep particles as described for the surface particles above. The Nd isotopic composition of particles from both depths $\left[\varepsilon_{\mathrm{Nd}}=-9.3\right.$ \pm 0.5 BATS $30 \mathrm{~m}$ (5 labs); $\varepsilon_{\mathrm{Nd}}=-13.8 \pm 0.6$ BATS $2000 \mathrm{~m} \mathrm{(4}$ labs)] is within the uncertainty of ambient seawater $\varepsilon_{\mathrm{Nd}}$ (Fig. 6), and no difference in isotopic composition is observed between the leached and digested samples from $2000 \mathrm{~m}$ water depth (van de Flierdt et al. 2012). This is in line with previous studies of particulate and ambient dissolved $\mathrm{Nd}$ isotope ratios in the North Atlantic and the Mediterranean Sea that show isotopic equilibrium between particulate and dissolved $\varepsilon_{\mathrm{Nd}}$ (Henry et al. 1994; Jeandel et al. 1995; Tachikawa et al. 1999).

Potential sources of particles to the Sargasso Sea are aerosols and dust, river runoff from the North American continent, and laterally advected particles. North American aerosols have lower $\varepsilon_{\mathrm{Nd}}$ values $\left(\varepsilon_{\mathrm{Nd}}=-14.1\right.$, Jeandel et al. 1995) than Saharan dust collected on Bermuda $\left(\varepsilon_{\mathrm{Nd}}=-13.2\right.$, Jeandel et al. 1995). The $\mathrm{Nd}$ isotopic composition of suspended particles from rivers draining the northeastern United States ranges from $\varepsilon_{\mathrm{Nd}}$ $=-11.3$ (Hudson River, Goldstein et al. 1984) to $\varepsilon_{\mathrm{Nd}}=-12.9$ and -13.6 (Goldstein and Jacobsen 1988). The $\mathrm{Nd}$ isotopic composition of particles from $30 \mathrm{~m}$ and $2000 \mathrm{~m}$ at BATS of $\varepsilon_{\mathrm{Nd}}$ $=-9.3 \pm 0.5$ and $\varepsilon_{\mathrm{Nd}}=-13.8 \pm 0.6$, respectively, is close to previously published particle $\varepsilon_{\mathrm{Nd}}$ values from the Sargasso Sea (Jeandel et al. 1995). Their close correspondence with ambient seawater $\varepsilon_{\mathrm{Nd}}$ of $-9.3 \pm 0.2(20 \mathrm{~m})$ and $-13.1 \pm 0.2(2000 \mathrm{~m})$ suggests that particulate and dissolved $\mathrm{Nd}$ are in isotopic equilibrium. These findings are consistent with the observations by Sholkovitz et al. (1994) that the largest fraction of particulate REE is contained in the easily leachable (with acetic acid) ferromanganese oxide coatings of marine particles.

It is, therefore, not surprising that the leached and digested samples from BATS have similar Nd isotopic compositions and are consistent with the dissolved $\varepsilon_{\mathrm{Nd}}$ of ambient seawater. This suggests that if the provenance of the suspended particles is of interest, Fe-Mn oxide coatings have to be thoroughly removed before analysis of the silicate fraction.

The concentration profiles of the light REE (LREE) (except Ce) and heavy REE (HREE) at BATS show an increase to 1000 $\mathrm{m}$ water depth, followed by relatively constant or slightly lower concentrations between $2000 \mathrm{~m}$ and $3000 \mathrm{~m}$ (Table 5, Fig. 8). The middle REE (MREE) vary little from the surface to $3000 \mathrm{~m}$ water depth. All REE concentrations rapidly increase below $3000 \mathrm{~m}$ to the bottom at $4500 \mathrm{~m}$ water depth. Cerium concentrations are highest near the surface $(20 \mathrm{~m}, 75 \mathrm{~m})$, lowest between $1000 \mathrm{~m}$ and $3000 \mathrm{~m}$ water depth, and increase again toward the bottom. This behavior is typical for Ce and reflects the oxidation of Ce from dissolved trivalent Ce to particulate tetravalent Ce within the upper water column, and remineralization at depth (Sholkovitz and Schneider 1991). Over the entire depth profile, the LREE reveal a stronger increase with depth than the HREE, e.g., La shows a 163\% increase with depth compared with a $42 \%$ increase of $\mathrm{Yb}$.

The sharp increase in concentrations across all REEs below $3000 \mathrm{~m}$ is coincident with a decrease in beam transmission measured by a transmissometer attached to the conductivitytemperature-depth (CTD) rosette on cruise KN193-6 (Fig. 6). The KN193-6 samples are located within or near the southern edge of the deep nepheloid layer, where sediments on the seafloor are resuspended by vigorous bottom currents (Biscaye and Eittreim 1977). Because dissolved and particulate REE concentrations are closely related (e.g., Jeandel et al. 1995; Siddall et al. 2008), the increase in REE concentrations at this depth $(>3000 \mathrm{~m}$ ) may be due to REE release from resuspended sediments in the bottom nepheloid layer. However, the observed Nd concentrations and isotope compositions of samples from this depth range are consistent with those from all nearby profiles including open ocean locations (Fig. 7), suggesting that the increase in REE concentrations is dominated by remineralization of sinking particles at depth and water mass advection rather than REE release from resuspended particles. Siddall et al. (2008) noted that downward transport of $\varepsilon_{\mathrm{Nd}}$ signatures through reversible scavenging does not overprint the advected $\varepsilon_{\mathrm{Nd}}$ signal in areas of strong lateral transport, such as the Atlantic, suggesting that remineralization at depth can increase $\mathrm{Nd}$ concentrations without significantly changing the deep water $\mathrm{Nd}$ isotopic composition. If surface particles at BATS were isolated from exchange with seawater through binding in biologically formed aggregates that only decompose at the seafloor, as suggested by Jeandel et al. (1995), this would not be inconsistent with the isotopic composition of bottom waters at BATS of $\varepsilon_{\mathrm{Nd}}=-12.6$, because particles entering the Sargasso Sea through rivers, dust, or as aerosols have $\varepsilon_{\mathrm{Nd}}$ values of -11 to -14 (Goldstein et al. 1984; Goldstein and Jacobsen 1988; Jeandel et al. 1995). Additionally, northward advection and mixing of relatively Nd- and Si- 


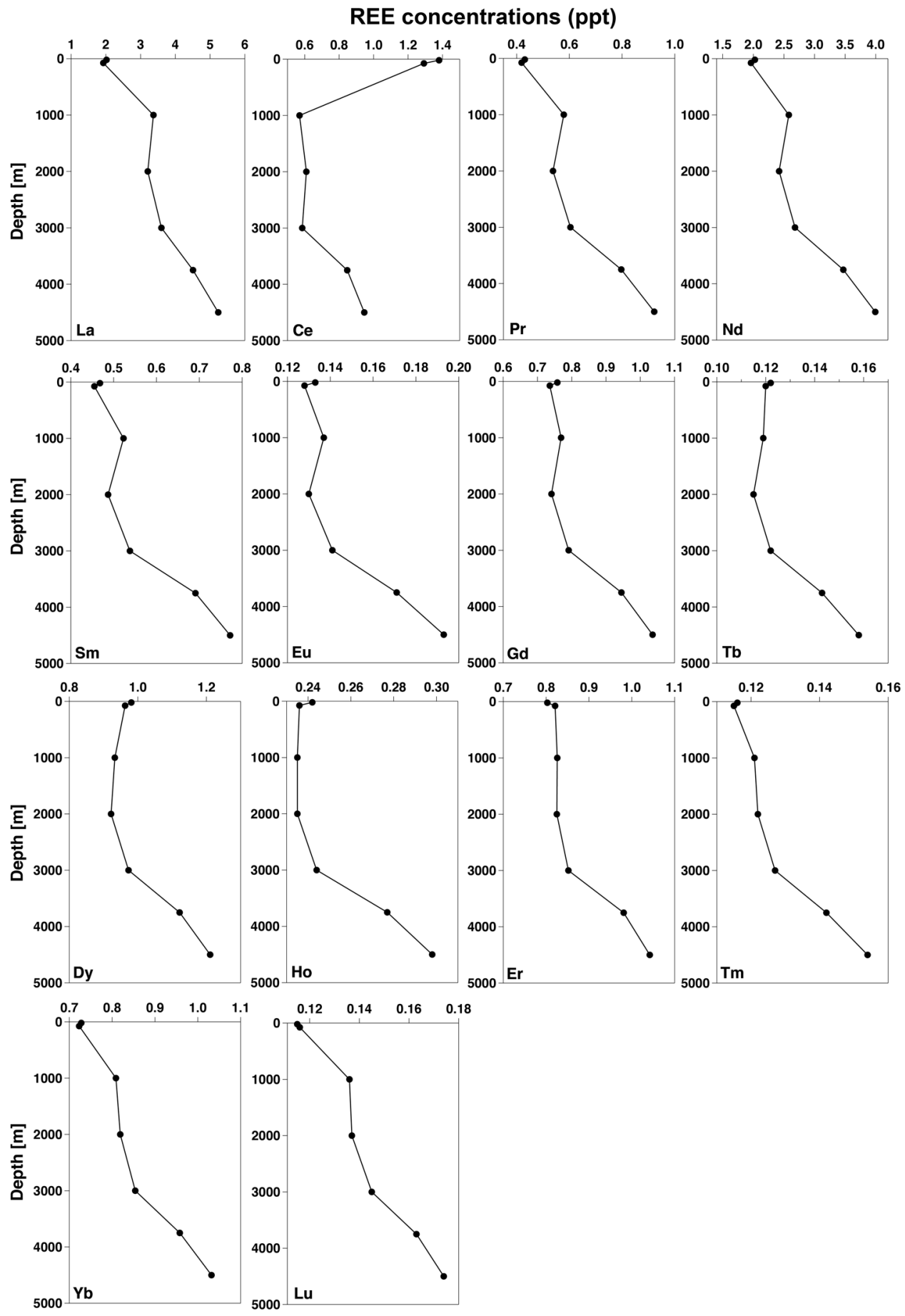

Fig. 8. Rare earth element baseline profiles at BATS.

rich, more radiogenic Antarctic Bottom Water (AABW) with southward flowing Nd- and Si-poor, less radiogenic NADW at depth could contribute to the $\mathrm{Nd}$ and $\mathrm{Si}$ increases and the small $\varepsilon_{\mathrm{Nd}}$ shift to higher values below $3000 \mathrm{~m}$ (Fig. 6).

Normalized to Post-Archean Australian Shale REE concentrations (PAAS, McLennan 1989), the REE patterns at all depths show a typical seawater pattern with an increase from LREE to
HREE, and a negative Ce anomaly (Fig. 9). Previously published REE profiles from BATS (Sholkovitz and Schneider 1991; Sholkovitz et al. 1994) show different REE/PAAS patterns. Absolute values differ from the data reported here for all but the surface samples $(15 \mathrm{~m}, 30 \mathrm{~m})$. In detail, at $1000 \mathrm{~m}$ and 2000 $\mathrm{m}$ water depth analyzed by both studies, previously published concentrations are higher by $0.5 \mathrm{pg} / \mathrm{g}(1000 \mathrm{~m})$ and $0.4 \mathrm{pg} / \mathrm{g}$ 

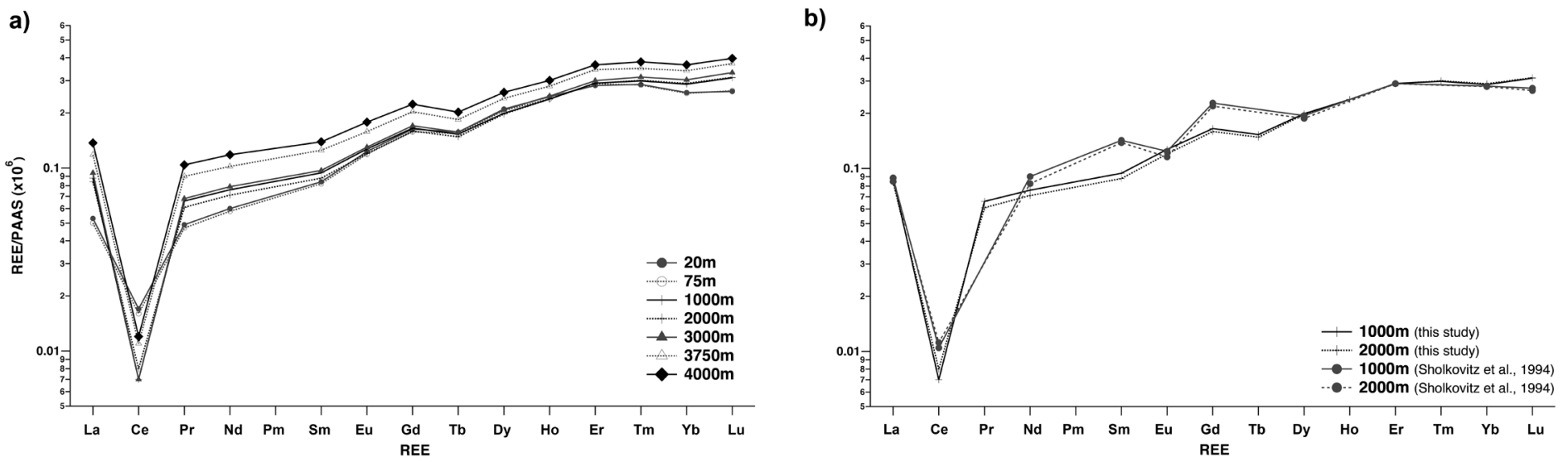

Fig. 9. Rare earth element concentrations at BATS normalized to average shale (Post Archean Australian Shale, PAAS, McLennan 1989). a) REE patterns from this study and b) comparison of REE patterns from $1000 \mathrm{~m}$ and $2000 \mathrm{~m}$ from this study and Sholkovitz et al. (1994).

(2000 m) for $\mathrm{Nd}, 0.3 \mathrm{pg} / \mathrm{g}(1000 \mathrm{~m}$ and $2000 \mathrm{~m})$ for $\mathrm{Sm}$, and 0.3 $\mathrm{pg} / \mathrm{g}(1000 \mathrm{~m}$ and $2000 \mathrm{~m})$ for $\mathrm{Gd}$, and a decrease from $\mathrm{Yb}$ to $\mathrm{Lu}$, while our data show an increase from $\mathrm{Yb}$ to $\mathrm{Lu}$ (Fig. 9). The trends and absolute concentrations of our data are supported by the REE intercalibration results from $15 \mathrm{~m}$ and $2000 \mathrm{~m}$ water depth at BATS (6 participating laboratories) that were collected at the same location and on the same cruise as our samples and that only differed by $9 \%(\mathrm{Nd}), 10 \%(\mathrm{Sm})$, and $11 \%$ (Gd) (van de Flierdt et al. 2012). The differences between our data and those of Sholkovitz et al. (1994), therefore, have to be attributed to either the different season and year the samples were collected in (this study: May-June 2008, Sholkovitz: April 1989), or to analytical uncertainties or spike calibration.

\section{SAFe baseline profile}

The water column profiles of $\mathrm{Nd}$ isotope ratios and concentrations at the northeast Pacific SAFe station were analyzed at the University of Hawaii (UH) and Imperial College London (ICL) and are shown in Table 6 and Fig. 10. The $\varepsilon_{\mathrm{Nd}}$ profiles show an average $\varepsilon_{\mathrm{Nd}}$ of -3.6 at $4500 \mathrm{~m}$ water depth and aradual increase to $\varepsilon_{\mathrm{Nd}}=-2.6$ at $2000 \mathrm{~m}$ and $\varepsilon_{\mathrm{Nd}}=-2.9$ at $1000 \mathrm{~m}$ water depth. The two shallowest samples analyzed at UH (500 $\mathrm{m}$ and $100 \mathrm{~m}$ ) deviate significantly from those analyzed at ICL: while the ICL $\varepsilon_{\mathrm{Nd}}$ values range between $\varepsilon_{\mathrm{Nd}}=-3.2$ and -3.4 , the $\mathrm{UH} \varepsilon_{\mathrm{Nd}}$ values show a decrease to $\varepsilon_{\mathrm{Nd}}=-4.2$ at $500 \mathrm{~m}$ and $\varepsilon_{\mathrm{Nd}}=-5.4$ at $100 \mathrm{~m}$ water depth. Both laboratories adhere to routine quality control through analysis of standards and blanks, and their measurements of $\mathrm{Nd}$ isotope ratios and concentrations on seawater as part of the international intercalibration exercise (BATS $20 \mathrm{~m}$ and $2000 \mathrm{~m}$, SAFe $2000 \mathrm{~m}$, and an unknown standard) agreed well with those of other laboratories (see van de Flierdt et al. 2012). We find no reason to discount any of the Nd isotope measurements of the upper water column profiles at SAFe. Possible reasons for the disagreement are either contamination during sampling on the ship or during chemical separation of $\mathrm{Nd}$ in the laboratory, or unknown complications during the analysis. We compare both profiles to the few available $\mathrm{Nd}$ isotope measurements in the North
Pacific but refrain from an in-depth discussion of the upper water column $\varepsilon_{\mathrm{Nd}}$ profile at SAFe until future analyses have confirmed the isotopic composition.

Published water column $\varepsilon_{\mathrm{Nd}}$ profiles from the North Pacific (Station BO-3, $30^{\circ} \mathrm{N} 160^{\circ} \mathrm{W}$; and Station BO-5 $20^{\circ} \mathrm{N}, 175^{\circ} \mathrm{W}$, Amakawa et al. 2009) to the west and southwest of SAFe, respectively, show similar (BO-3) to slightly lower (BO-5) $\varepsilon_{\mathrm{Nd}}$ values below $1000 \mathrm{~m}$ water depths than those at SAFe and a minimum of $\varepsilon_{\mathrm{Nd}}=-3.3(\mathrm{BO}-3)$ and $-2.7(\mathrm{BO}-5)$ at $1000 \mathrm{~m}$ water depth (Figs. 1 and 11). This relatively homogenous vertical isotopic composition suggests no significant influence of more unradiogenic Antarctic Bottom Water (AABW) at depth, in contrast to the central and western North Pacific, where bottom water $\varepsilon_{\mathrm{Nd}}$ values decrease to $\varepsilon_{\mathrm{Nd}}=-4.5$ and -5.8 (Piepgras and Jacobsen 1988; Amakawa et al. 2004; Amakawa et al. 2009) (Fig. 11).

The higher $\varepsilon_{\mathrm{Nd}}$ values between $500 \mathrm{~m}$ and $850 \mathrm{~m}$ water depth at SAFe $\left(\varepsilon_{\mathrm{Nd}}=-3.0\right.$ to -4.2$)$ coincide with the depth range of North Pacific Intermediate Water (NPIW, core layer density $\sigma(=26.9$, You 2003) at this location, that is associated with a salinity minimum (Yasuda 2004). NPIW is formed in the western North Pacific through mixing of subpolar water and older subtropical water of the same density and is incorporated into the North Pacific subtropical gyre (Talley 1997). The $\varepsilon_{\mathrm{Nd}}$ values of NPIW at SAFe of both profiles are similar with $\mathrm{Nd}$ isotope ratios that have previously been reported for NPIW near its formation region $\left(\varepsilon_{\mathrm{Nd}}=-3.2 ; 40^{\circ} \mathrm{N}, 160^{\circ} \mathrm{E}\right.$, Amakawa et al. 2004), and near the Hawaiian Islands $\left(\varepsilon_{\mathrm{Nd}}=\right.$ -3.7, Vance et al. 2004).

The shift to lower values of $\varepsilon_{\mathrm{Nd}}=-4.2(500 \mathrm{~m})$ and $\varepsilon_{\mathrm{Nd}}=-5.4$ $(200 \mathrm{~m})$ in the profile analyzed at $\mathrm{UH}$ is consistent with the gradual $\varepsilon_{\mathrm{Nd}}$ decrease at BO-3 $\left(\varepsilon_{\mathrm{Nd}}=-5.6,200 \mathrm{~m}\right)$ and BO-5 $\left(\varepsilon_{\mathrm{Nd}}\right.$ $=-4.9,200 \mathrm{~m})\left(\right.$ Fig. 11). The upper water column $\varepsilon_{\mathrm{Nd}}$ values analyzed at ICL $\left(\varepsilon_{\mathrm{Nd}}=-3.2\right.$ to -3.4$)$, on the other hand, agree with the isotopic composition of subsurface waters (300-600 $\mathrm{m})$ around Hawaii $\left(20-22.8^{\circ} \mathrm{N}, 156-158^{\circ} \mathrm{W}\right)$ of $\varepsilon_{\mathrm{Nd}}=-3.3$ to -3.7 (Fig. 11). 
Table 6: Nd isotope ratio and concentration baseline profiles at $\mathrm{SAFe}\left(30^{\circ} \mathrm{N}, 140^{\circ} \mathrm{E}\right)$

\begin{tabular}{|c|c|c|c|c|c|c|c|c|c|c|c|c|c|c|c|c|c|}
\hline $\begin{array}{c}\text { water } \\
\text { depth }[\mathrm{m}]\end{array}$ & $\begin{array}{l}\text { sigma-t } \\
{\left[\mathrm{kg} / \mathrm{m}^{3}\right]}\end{array}$ & $\begin{array}{c}\text { pot. Temp. } \\
{\left[{ }^{\circ} \mathrm{C}\right]}\end{array}$ & Salinity & filter type & sample ID & $\begin{array}{l}\text { sample } \\
\text { volume }^{a}\end{array}$ & $\begin{array}{c}{ }^{143} \mathrm{Nd} /{ }^{144} \mathrm{Nd} \\
\text { measured }\end{array}$ & & $\begin{array}{c}\text { internal } \\
2 \sigma \mathrm{SE}\end{array}$ & $\begin{array}{l}{ }^{143} \mathrm{Nd} /{ }^{144} \mathrm{Nd} \\
\text { normalized }\end{array}$ & $\varepsilon_{\mathrm{Nd}}^{\mathrm{c}}$ & & $\begin{array}{c}\text { internal } \\
2 \sigma \mathrm{SE}\end{array}$ & $\begin{array}{l}\text { external } \\
2 \sigma \mathrm{SD}^{d}\end{array}$ & $\begin{array}{c}\mathrm{Nd} \\
{[\mathrm{ppt}]}\end{array}$ & & $\begin{array}{l}\text { internal } \\
\% 2 \sigma \mathrm{SE}\end{array}$ \\
\hline 20 & 24.769 & 19.23 & 34.75 & AcroPak $0.8 / 0.45 \mu \mathrm{m}$ & KN195-8-Nd-2323 & $0.25 \mathrm{~L}$ & & & & & & & & & 0.9 & \pm & 1.4 \\
\hline 100 & 25.172 & 18.06 & 34.89 & AcroPak $0.8 / 0.45 \mu \mathrm{m}$ & KN195-8-Nd-2321 & $5 \mathrm{~L}, 0.25 \mathrm{~L}$ & 0.512343 & \pm & 0.000014 & 0.512362 & -5.4 & \pm & 0.3 & 0.3 & 1.1 & \pm & 1.8 \\
\hline 500 & 26.707 & 6.43 & 34.01 & AcroPak $0.8 / 0.45 \mu \mathrm{m}$ & KN195-8-Nd-2318 & $5 \mathrm{~L}, 0.25 \mathrm{~L}$ & 0.512406 & \pm & 0.000006 & 0.512425 & -4.2 & \pm & 0.1 & 0.3 & 2.2 & \pm & 0.7 \\
\hline 850 & 27.215 & 4.11 & 34.31 & AcroPak $0.8 / 0.45 \mu \mathrm{m}$ & KN195-8-Nd-2314 & $5 \mathrm{~L}, 0.25 \mathrm{~L}$ & 0.512454 & \pm & 0.000009 & 0.512473 & -3.2 & \pm & 0.2 & 0.3 & 2.8 & \pm & 1.0 \\
\hline 1000 & 27.340 & 3.69 & 34.41 & AcroPak 0.8/0.45 $\mu \mathrm{m}$ & KN195-8-Nd-2311 & $5 \mathrm{~L}, 0.25 \mathrm{~L}$ & 0.512468 & \pm & 0.000005 & 0.512487 & -2.9 & \pm & 0.1 & 0.3 & 2.8 & \pm & 1.1 \\
\hline 2000 & 27.663 & 1.88 & 34.62 & AcroPak $0.8 / 0.45 \mu \mathrm{m}$ & KN195-8-Nd-2308 & $0.25 \mathrm{~L}$ & & & & & & & & & 4.3 & \pm & 1.8 \\
\hline 3000 & 27.736 & 1.33 & 34.66 & AcroPak $0.8 / 0.45 \mu \mathrm{m}$ & KN195-8-Nd-2305 & $5 \mathrm{~L}, 0.25 \mathrm{~L}$ & 0.512456 & \pm & 0.000004 & 0.512475 & -3.2 & \pm & 0.1 & 0.3 & 6.4 & \pm & 1.4 \\
\hline 4500 & 27.753 & 1.14 & 34.68 & AcroPak 0.8/0.45 $\mu \mathrm{m}$ & KN195-8-Nd-2302 & $5 \mathrm{~L}, 0.25 \mathrm{~L}$ & 0.512427 & \pm & 0.000004 & 0.512446 & -3.7 & \pm & 0.1 & 0.3 & 7.8 & \pm & 0.6 \\
\hline \multicolumn{18}{|c|}{ analyzed at Imperial College London } \\
\hline $\begin{array}{c}\text { water } \\
\text { depth [m] }\end{array}$ & $\begin{array}{l}\text { sigma-t } \\
{\left[\mathrm{kg} / \mathrm{m}^{3}\right]}\end{array}$ & $\begin{array}{l}\text { pot. Temp. } \\
{\left[{ }^{\circ} \mathrm{C}\right]}\end{array}$ & Salinity & filter type & sample ID & $\begin{array}{l}\text { sample } \\
\text { volume }\end{array}$ & $\begin{array}{c}{ }^{143} \mathrm{Nd} /{ }^{144} \mathrm{Nd} \\
\text { measured }\end{array}$ & & $\begin{array}{c}\text { internal } \\
2 \sigma \mathrm{SE}\end{array}$ & $\begin{array}{l}{ }^{143} \mathrm{Nd} /{ }^{144} \mathrm{Nd} \\
\text { normalized }^{\mathrm{e}}\end{array}$ & $\varepsilon_{\mathrm{Nd}}^{\mathrm{c}}$ & & $\begin{array}{c}\text { internal } \\
2 \sigma \mathrm{SE}\end{array}$ & $\begin{array}{l}\text { external } \\
2 \sigma \mathrm{SD}^{d}\end{array}$ & $\begin{array}{c}\mathrm{Nd} \\
{[\mathrm{ppt}]}\end{array}$ & & $\begin{array}{l}\text { internal } \\
\% 2 \sigma \mathrm{SE}\end{array}$ \\
\hline 20 & 24.769 & 19.23 & 34.75 & AcroPak $0.8 / 0.45 \mu \mathrm{m}$ & KN195-8-Nd-2324 & $5 \mathrm{~L}$ & 0.512450 & \pm & 0.000019 & 0.512463 & -3.4 & \pm & 0.4 & 0.2 & 0.8 & \pm & 0.01 \\
\hline 100 & 25.172 & 18.06 & 34.89 & AcroPak 0.8/0.45 $\mu \mathrm{m}$ & KN195-8-Nd-2320 & $5 \mathrm{~L}$ & 0.512463 & \pm & 0.000011 & 0.512475 & -3.2 & \pm & 0.2 & 0.2 & 1.0 & \pm & 0.01 \\
\hline 500 & 26.707 & 6.43 & 34.01 & AcroPak $0.8 / 0.45 \mu \mathrm{m}$ & KN195-8-Nd-2317 & $5 \mathrm{~L}$ & 0.512458 & \pm & 0.000016 & 0.512471 & -3.3 & \pm & 0.3 & 0.2 & 2.1 & \pm & 0.01 \\
\hline 850 & 27.215 & 4.11 & 34.31 & AcroPak $0.8 / 0.45 \mu \mathrm{m}$ & KN195-8-Nd-2315 & $5 \mathrm{~L}$ & 0.512470 & \pm & 0.000021 & 0.512483 & -3.0 & \pm & 0.4 & 0.2 & 2.8 & \pm & 0.02 \\
\hline 1000 & 27.340 & 3.69 & 34.41 & AcroPak 0.8/0.45 $\mu \mathrm{m}$ & KN195-8-Nd-2312 & $5 \mathrm{~L}$ & 0.512481 & \pm & 0.000018 & 0.512494 & -2.8 & \pm & 0.3 & 0.2 & 2.9 & \pm & 0.02 \\
\hline 2000 & 27.663 & 1.88 & 34.62 & AcroPak $0.8 / 0.45 \mu \mathrm{m}$ & KN195-8-Nd-2309 & $5 \mathrm{~L}$ & 0.512490 & \pm & 0.000008 & 0.512503 & -2.6 & \pm & 0.2 & 0.2 & 4.3 & \pm & 0.01 \\
\hline 3000 & 27.736 & 1.33 & 34.66 & AcroPak $0.8 / 0.45 \mu \mathrm{m}$ & KN195-8-Nd-2306 & $5 \mathrm{~L}$ & 0.512467 & \pm & 0.000008 & 0.512479 & -3.1 & \pm & 0.2 & 0.2 & 6.4 & \pm & 0.01 \\
\hline 4500 & 27.753 & 1.14 & 34.68 & AcroPak $0.8 / 0.45 \mu \mathrm{m}$ & KN195-8-Nd-2303 & $5 \mathrm{~L}$ & 0.512447 & \pm & 0.000005 & 0.512460 & -3.5 & \pm & 0.1 & 0.2 & 7.8 & \pm & 0.00 \\
\hline
\end{tabular}

${ }^{\mathrm{a}}$ sample volume for isotope analyses $=5 \mathrm{~L}$, for Nd concentrations $\sim 250 \mathrm{~mL}$.

${ }^{\mathrm{b}} \mathrm{UH}$ : normalized to repeat analyses of La Jolla of ${ }^{143} \mathrm{Nd} /{ }^{144} \mathrm{Nd}=0.511839 \pm 0.000014(\mathrm{n}=5)$, relative to a La Jolla value of 0.511858 (Lugmair et al., 1983 ).

${ }^{\mathrm{c}} \varepsilon_{\mathrm{Nd}}$ values were calculated relative to a CHUR of 0.512638 (Jacobsen and Wasserburg, 1980).

d external errors are derived from repeat standard analyses over the period of sample measurements (10ng at UH, $5 \mathrm{ng}$ at ICL);

if internal errors are larger than external errors, these are plotted.

${ }^{\mathrm{e}} \mathrm{ICL}$ : normalized to repeat analyses of $\mathrm{JNd}_{\mathrm{i}}$ of ${ }^{143} \mathrm{Nd} /{ }^{144} \mathrm{Nd}=0.512102 \pm 0.000003(\mathrm{n}=5)$, relative to a $\mathrm{JNd}_{\mathrm{i}}$ value of $0.512115(\mathrm{Tanaka}$ et al., 2000$)$.

UH: reports an external reproducibility of $0.14 \mathrm{ppt}$ based on $\mathrm{n}=7$ aliquots of a seawater sample

ICL: reports an external reproducibility of $5.6 \%(2 \sigma \mathrm{SE})$ based on $n=5$ repeat analyses of rock standard BCR

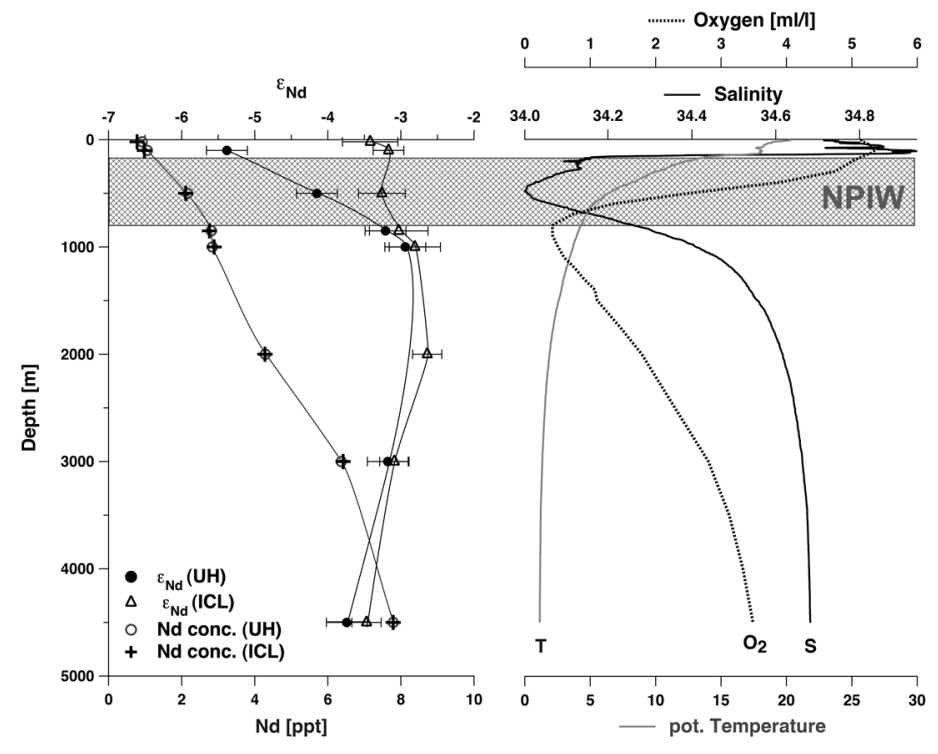

Fig. 10. Seawater $\mathrm{Nd}$ isotope ratio (in $\varepsilon_{\mathrm{Nd}}$ notation) and $\mathrm{Nd}$ concentration baseline profiles at SAFe analyzed at UH (circles) and ICL (triangles and crosses). Epsilon $\mathrm{Nd}$ errors plotted are external two sigma standard deviations. Two sigma standard errors of $\mathrm{Nd}$ concentrations are smaller than the symbols for $\mathrm{Nd}$ concentrations in the plot. Potential temperature, salinity (KN195-8 CTD data), and dissolved oxygen (Levitus and Boyer 1994) are shown for comparison. NPIW = North Pacific Intermediate Water.
The Nd concentration profiles at SAFe of both laboratories agree well (maximum difference of $0.1 \mathrm{ppt} \mathrm{Nd}$ ) and show a gradual increase from an average surface $\mathrm{Nd}$ concentration of $0.85 \mathrm{ppt}$ to a bottom water Nd concentration of $7.8 \mathrm{ppt}$ (Fig. 8), reflecting the typical behavior of $\mathrm{Nd}$ in the ocean of scavenging in the upper water column and remineralization at depth.

\section{Conclusions and recommendations}

The nature of the GEOTRACES program requires careful testing and evaluation of the techniques and materials to be used to collect, process, and analyze the seawater samples. In an effort to provide this basis for the analysis of $\mathrm{Nd}$ isotope ratios and concentrations in seawater, we have tested different filter materials and pore sizes, two widely used sampling bottles, and two methods for the preconcentration of REEs from seawater at three different locations.

The comparison of five different filter types and pore sizes with unfiltered seawater suggests that dissolved Nd isotope ratios and $\mathrm{Nd}$ concentrations of seawater are not affected by the choice of the filter (Nuclepore, Supor, QMA), filter type (membrane, cartridge), or pore size $(0.2,0.45,0.8,1.0 \mu \mathrm{m})$. At all locations chosen for this study, Bermuda Atlantic TimeSeries Study (BATS) station (20 m and $2000 \mathrm{~m}$ water depth) and the depth of the chlorophyll maximum at a site on the Virginia continental slope, the $\mathrm{Nd}$ isotope ratios and $\mathrm{Nd}$ con- 


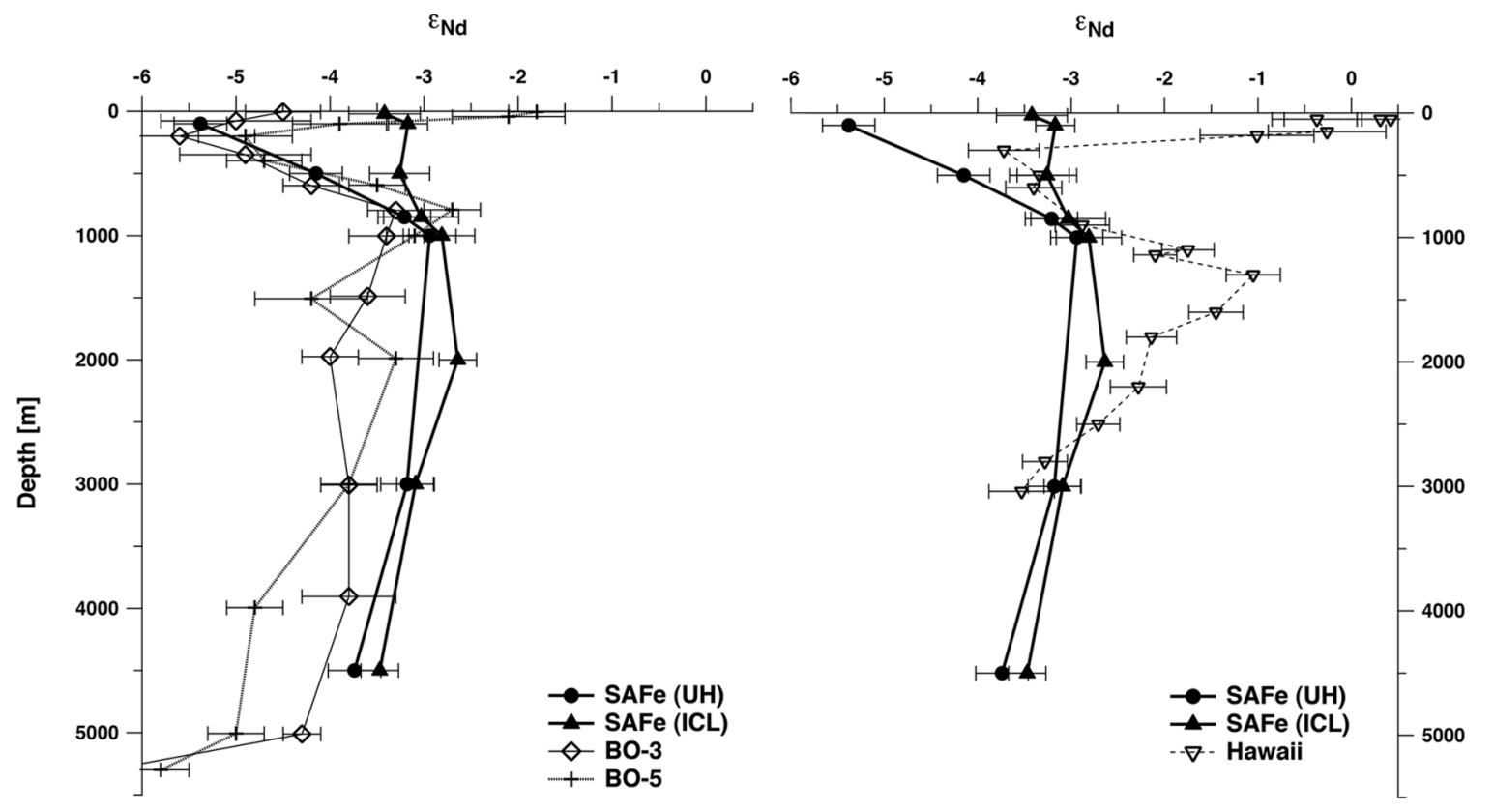

Fig. 11. Seawater $\mathrm{Nd}$ isotope ratio profiles (in $\varepsilon_{\mathrm{Nd}}$ notation) at SAFe compared with other North Pacific $\varepsilon_{\mathrm{Nd}}$ water column profiles. a) $\varepsilon_{\mathrm{Nd}}$ profiles at $\mathrm{SAFe}$ analyzed at the University of Hawaii (UH) and Imperial College London (ICL) (filled symbols) compared to $\varepsilon_{\mathrm{Nd}}$ profiles at $\mathrm{BO}-3$ ( $30^{\circ} \mathrm{N} 160^{\circ} \mathrm{W}$, Amakawa et al. 2009) and BO-5 (20 $\mathrm{N}, 175^{\circ} \mathrm{W}$, Amakawa et al. 2009) (open symbols). b) Same as in a) but in comparison with water column $\varepsilon_{\mathrm{Nd}}$ from stations around Hawaii combined to one profile $\left(20-22.8^{\circ} \mathrm{N}, 156-158^{\circ} \mathrm{W}\right)$ (Vance et al. 2004).

centrations of filtered and unfiltered seawater were the same within the uncertainty of the analysis: $\leq 56 \mathrm{ppm}(2 \sigma$ standard deviation) for ${ }^{143} \mathrm{Nd} /{ }^{144} \mathrm{Nd}$ ratios, and $\leq 10 \%(2 \sigma \mathrm{RSD})$ for $\mathrm{Nd}$ concentrations. The international GEOTRACES intercalibration of $\mathrm{Nd}$ isotopes and REE concentrations achieved very similar reproducibilities of $\leq 60 \mathrm{ppm}$ and $\leq 9 \%$ (van de Flierdt et al. 2012), suggesting that the results from our filter tests are within the analytical uncertainty for sample sizes of 5-15 ng $\mathrm{Nd}$. Therefore, the assumption made in previous studies that at most locations filtration is not required may be justified. However, the sites studied here may not be representative of all possible scenarios in the global ocean in terms of particle flux and isotopic composition of suspended particles relative to ambient seawater. We therefore highly recommend routine filtration of seawater samples using any of the filter material tested here with a pore size of $0.45 \mu \mathrm{m}$ or less, particularly in high-particle environments such as areas of high dust flux, river discharge, and/or within bottom or detached nepheloid layers. This applies especially to areas where suspended particles are expected to have a different isotopic composition than local seawater.

Our tests of two different sampling bottles, standard Niskin versus trace metal-clean GO-FLO bottles, confirm the general notion that trace metal-clean sampling equipment is not necessary for obtaining accurate $\mathrm{Nd}$ isotope and concentration data from seawater samples. Moreover, we observed no difference in dissolved $\mathrm{Nd}$ isotope ratios between two commonly used methods for the preconcentration of REEs from seawater, Fe coprecipitation, and C18 cartridges. Both methods are therefore applicable and suited for the purposes of the GEOTRACES program.

Neodymium isotope ratios of suspended particles at $30 \mathrm{~m}$ and $2000 \mathrm{~m}$ water depth at BATS indicate isotopic equilibrium with ambient seawater, suggesting thorough removal of FeMn-oxide coatings is required if the provenance of suspended particles is of interest.

The baseline profiles for BATS in the western North Atlantic $\left(\varepsilon_{\mathrm{Nd}}\right.$ and REE) and SAFe in the eastern North Pacific $\left(\varepsilon_{\mathrm{Nd}} ;\right.$ results $>800 \mathrm{~m}$ water depths), are recommended for inclusion in future cruises for continued quality control, intercalibration, and method validation. The Nd isotopic composition at shallow water depths at SAFe needs to be further constrained on future expeditions.

\section{References}

Alibo, D. S., and Y. Nozaki. 1999. Rare earth elements in seawater: Particle association shale-normalization, and Ce oxidation. Geochim. Cosmochim. Acta 63:363-372 [doi:10.1016/S0016-7037(98)00279-8].

Amakawa, H., Y. Nozaki, D. S. Alibo, J. Zhang, K. Fukugawa, and H. Nagai. 2004. Neodymium isotopic variations in Northwest Pacific waters. Geochim. Cosmochim. Acta 68:715-727 [doi:10.1016/S0016-7037(03)00501-5].

—, K. Sasaki, and M. Ebiharab. 2009. Nd isotopic composition in the central North Pacific. Geochim. Cosmochim. Acta 73:4705-4719 [doi:10.1016/j.gca.2009.05.058].

Andersson, P.S., D. Porcelli, M. Frank, G. Björk, R. Dahlqvist, Ö. Gustafsson. 2008. Neodymium isotopes in seawater 
from the Barents Sea and Fram Strait Arctic-Atlantic gateways. Geochim. Cosmochim. Acta 72:2854-2867 [doi:10.1016/j.gca.2008.04.008].

Biscaye, P. E., and S. L. Eittreim. 1977. Suspended particulate loads and transports in the nepheloid layer of the abyssal Atlantic Ocean. Mar. Geol. 23:155-172 [doi:10.1016/00253227(77)90087-1].

Choppin, G. R., and R. J. Silva. 1956. Separation of the lanthanides by ion exchange with alpha-hydroxy isobutyric acid. J. Inorg. Nucl. Chem. 3(2):153-154 [doi:10.1016/00221902(56)80076-6].

Cullen, J. T., and R. M. Sherrell. 1999. Techniques for determination of trace metals in small samples of size-fractionated particulate matter: phytoplankton metals off central California. Mar. Chem. 67:233-247 [doi:10.1016/S03044203(99)00060-2].

Dodson, R.W., G.J. Forney, E.H. Swift. 1936. The extraction of ferric chloride from hydrochloric acid solutions by isopropyl ether. J. Am. Chem. Soc. 58:2573-2577 [doi:10.1021/ja01303a058].

Garcia, H.E., R.A. Locarnini, T.P. Boyer, J.I. Antonov. 2006. World ocean atlas 2005, Vol. 4: Nutrients (phosphate, nitrate, silicate), p. 396. In S. Levitus [ed.], NOAA atlas NESDIS 64. U.S. Government Printing Office.

Goldstein, S. J., and S. B. Jacobsen. 1988. Nd and Sr isotopic systematics of river water suspended material: implications for crustal evolution. Earth. Planet. Sci. Lett. 87:249-265 [doi:10.1016/0012-821X(88)90013-1].

Goldstein, S.L., R.K. O'Nions, P.J. Hamilton. 1984. A Sm-Nd isotopic study of atmospheric dusts and particulates from major river systems. Earth. Planet. Sci. Lett. 70:221-236 [doi:10.1016/0012-821X(84)90007-4].

Hanawa, K., and L. D. Talley. 2001. Mode waters, pp. 373-400. In $\mathrm{G}$. Siedler [ed.], Ocean circulation and climate. Academic Press [doi:10.1016/S0074-6142(01)80129-7].

Henry, F., C. Jeandel, B. Dupre, J.F. Minster. 1994. Particulate and dissolved $\mathrm{Nd}$ in the western Mediterranean Sea: Sources, fate and budget. Mar. Chem. 45:283-305 [doi:10.1016/0304-4203(94)90075-2].

Jacobsen, S. B., and G. J. Wasserburg 1980. Sm-Nd isotopic evolution of chondrites. Earth. Planet. Sci. Lett. 50:139-155 [doi:10.1016/0012-821X(80)90125-9].

Jeandel, C. 1993. Concentration and isotopic composition of $\mathrm{Nd}$ in the South-Atlantic Ocean. Earth. Planet. Sci. Lett. 117:581-591 [doi:10.1016/0012-821X(93)90104-H].

, J.K. Bishop, A. Zindler. 1995. Exchange of neodymium and its isotopes between seawater and small and large particles in the Sargasso Sea. Geochim. Cosmochim. Acta 59:535-547 [doi:10.1016/0016-7037(94)00367-U].

—, D. Thouron, M. Fieux. 1998. Concentrations and isotopic compositions of neodymium in the eastern Indian Ocean and Indonesian straits. Geochim. Cosmochim. Acta 62:2597-2607 [doi:10.1016/S0016-7037(98)00169-0].

Jones, K. M. 2010. An evaluation of radiogenic isotopes as trac- ers of ocean circulation and sediment transport: modeling, seawater, and sediment studies. PhD thesis, Columbia Univ.

Lacan, F., and C. Jeandel. 2004a. Subpolar Mode Water formation traced by neodymium isotopic composition. Geophys. Res. Lett. 31. [doi:10.1029/2004GL019747].

— and rare earth element concentrations in the deep and intermediate Nordic Seas: Constraints on the Iceland Scotland Overflow Water signature. Geochem. Geophys. Geosyst. 5:Q11006 [doi:10.1029/2004GC000742].

— and 2005. Acquisition of the neodymium isotopic composition of the North Atlantic Deep Water. Geochem. Geophys. Geosyst. 6:Q120008. [doi:10.1029/ 2005GC000956].

Levitus, S., and T. P. Boyer. 1994. World ocean atlas 1994: Oxygen. U.S. Dept. of Commerce.

Lugmair, G.W., T. Shimamura, R.S. Lewis, E. Anders. 1983. Samarium-146 in the early solar system: Evidence from Neodymium in the Allende Meteorite. Science 222:10151018 [doi:10.1126/science.222.4627.1015].

McCartney, M. S. 1982. The subtropical recirculation of mode water. J. Mar. Res. 40(Suppl.):427-464.

McLennan, S. M. 1989. Rare earth elements in sedimentary rocks; influence of provenance and sedimentary processes. Rev. Mineral. Geochem. 21:169-200.

Measures, C., W.M. Landing, M.T. Brown, C.S. Buck. 2008. A commercially available rosette system for trace metal clean sampling. Limnol. Oceanogr. Methods 6:384-394 [doi:10.4319/lom.2008.6.384].

Piepgras, D.J., G.J. Wasserburg, E.J. Dasch. 1979. The isotopic composition of $\mathrm{Nd}$ in different ocean masses. Earth. Planet. Sci. Lett. 45:223-236 [doi:10.1016/0012-821X(79)90125-0]. - and G. J. Wasserburg. 1980. Neodymium isotopic variations in seawater. Earth. Planet. Sci. Lett. 50:128-138 [doi:10.1016/0012-821X(80)90124-7].

— western North-Atlantic inferred from $\mathrm{Nd}$ isotopic observations. Geochim. Cosmochim. Acta 51:1257-1271 [doi:10.1016/0016-7037(87)90217-1].

- and S. B. Jacobsen. 1988. The isotopic composition of neodymium in the North Pacific. Geochim. Cosmochim. Acta 52:1373-1381 [doi:10.1016/0016-7037(88)90208-6].

Pin, C., and J. F. S. Zalduegui. 1997. Sequential separation of light rare-earth elements, thorium and uranium by miniaturized extraction chromatography: Application to isotopic analyses of silicate rocks. Anal. Chim. Acta 339(1-2):79-89 [doi:10.1016/S0003-2670(96)00499-0].

Rickli, J., M. Frank, A.N. Halliday. 2009. The hafniumneodymium isotopic composition of Atlantic seawater. Earth. Planet. Sci. Lett. 280:118-127 [doi:10.1016/j.epsl.2009.01.026].

Shabani, M.B., T. Akagi, A. Masuda. 1992. Preconcentration of trace rare-earth elements in seawater by complexation with bis(2-ethylhexyl) hydrogen phosphate and 2-ethylhexyl dihydrogen phosphate adsorbed on a C18 cartridge and 
determination by inductively coupled plasma mass-spectrometry. Anal. Chem. 64:737-743 [doi:10.1021/ac00031 a008].

Sholkovitz, E. R., and D. L. Schneider. 1991. Cerium redox cycles and rare earth elements in the Sargasso Sea. Geochim. Cosmochim. Acta 55:2737-2743 [doi:10.1016/ 0016-7037(91)90440-G].

, W.M. Landing, B.L. Lewis. 1994. Ocean particle chemistry: The fractionation of rare earth elements between suspended particles and seawater. Geochim. Cosmochim. Acta 58:1567-1579 [doi:10.1016/0016-7037(94)90559-2].

Siddall, M., S. Khatiwala, T. van de Flierdt, K. Jones, S.L. Goldstein, S. Hemming, R.F. Anderson, 2008. Towards explaining the $\mathrm{Nd}$ paradox using reversible scavenging in an ocean general circulation model. Earth Planet. Sci. Lett. 274, 448461 [doi:10.1016/j.epsl.2008.07.044].

Stichel, T., M. Frank, J. Rickli, B.A. Haley. 2012. The hafnium and neodymium isotope composition of seawater in the Atlantic sector of the Southern Ocean. Earth Planet. Sci. Lett. 317-318:282-294 [doi:10.1016/j.epsl.2011.11.025].

Tachikawa, K., C. Jeandel, B. Dupre. 1999. Distribution of rare earth elements and neodymium isotopes in settling particulate material of the tropical Atlantic Ocean (EUMELI site). Deep-Sea Res. I 44:1769-1792 [doi:10.1016/S09670637(97)00057-5].

Talley, L. D. 1997. North Pacific Intermediate Water Transports in the Mixed Water Region. J. Phys. Oceanogr. 27:17951803 [doi:10.1175/1520-0485(1997)027<1795:NPIWTI> 2.0.CO;2].
Tanaka, T., and others. 2000. JNdi-1: a neodymium isotopic reference in consistency with LaJolla neodymium. Chem. Geol. 168(3-4):279-281 [doi:10.1016/S0009-2541(00)00198-4].

Tsuchiya, M. 1989. Circulation of the Antarctic Intermediate Water in the North-Atlantic Ocean. J. Mar. Res. 47:747-755 [doi:10.1357/002224089785076136].

van de Flierdt, T., and others. 2012. GEOTRACES intercalibration of neodymium isotopes and rare earth elements in seawater and marine particulates. Part 1: international intercomparison. Limnol. Oceanogr. Methods 10:234-251 [doi:10.4319/lom.2012.10.234].

Vance, D., A.E. Scrivner, P. Beney, M. Staubwasser, G.M. Henderson, N.C. Slowey. 2004. The use of foraminifera as a record of the past neodymium isotope composition of seawater. Paleoceanography 19 [doi:10.1029/2003PA000957].

Worthington, L. V. 1959. The $18^{\circ}$ water in the Sargasso Sea. Deep Sea Res. 5:297-305.

Yasuda, I. 2004. North Pacific Intermediate Water: Progress in SAGE (SubArctic Gyre Experiment) and Related Projects. J. Oceanogr. 60:385-395 [doi:10.1023/B:JOCE.0000038344. 25081.42].

You, Y. 2003. The pathway and circulation of North Pacific Intermediate Water. Geophys. Res. Lett. 30:2291 [doi:10.1029/2003GL018561].

Submitted 9 August 2011 Revised 7 February 2012 Accepted 14 February 2012 